\title{
Temporal trends in probabilistic maturation reaction norms and growth of Atlantic cod Gadus morhua on the Icelandic shelf
}

Heidi Pardoe (heidi@hafro.is)

Anssi Vainikka (anssi.vainikka@fiskeriverket.se)

Gudmundur Thórdarson (gudthor@hafro.is)

Gudrun Marteinsdóttir (runam@hafro.is)

Mikko Heino (mikko.heino@imr.no)

\section{Approved by}

Ulf Dieckmann

Leader, Evolution and Ecology Program

May 2010 


\section{Contents}

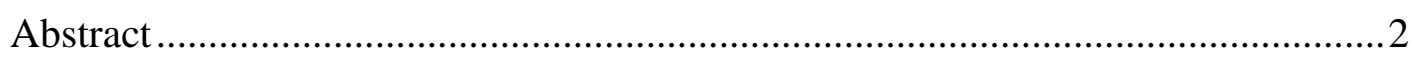

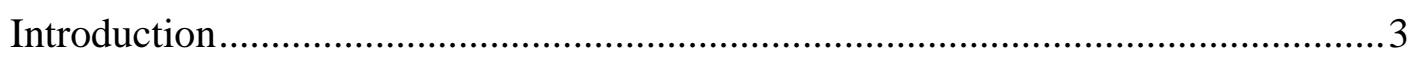

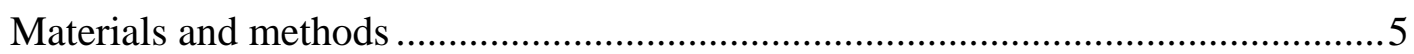

Data

Probabilistic maturation reaction norm (PMRN) maturation ..............................6

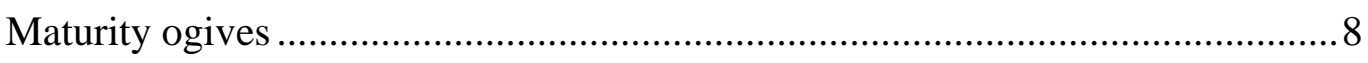

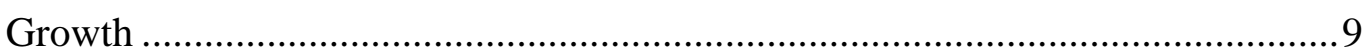

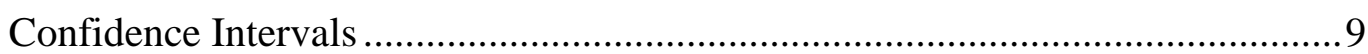

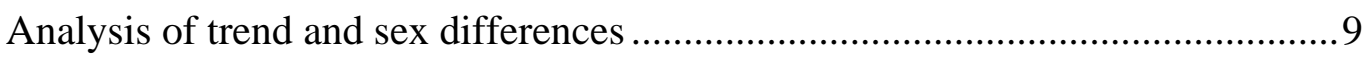

Potential explanatory variables of Lp50 trends ................................................. 10

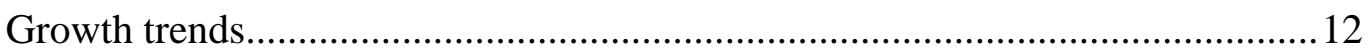

Effect of earlier maturation on growth.........................................................12

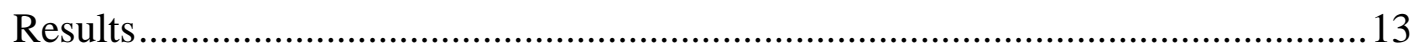

Length-at-age.................................................. 13

Probabilistic maturation reaction norms.................................. 13

Potential variables explaining trends in PMRN's........................... 14

Effect of earlier maturation on growth...................................16

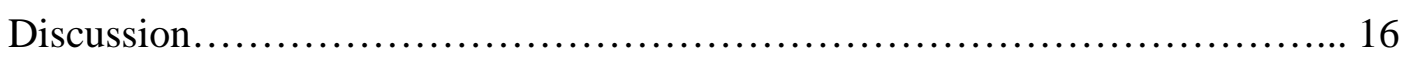

Acknowledgments.....................................................24

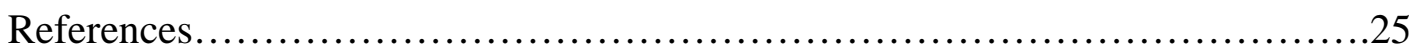

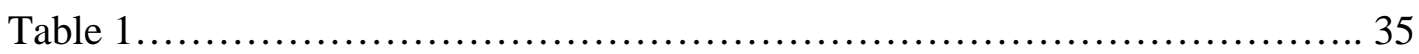

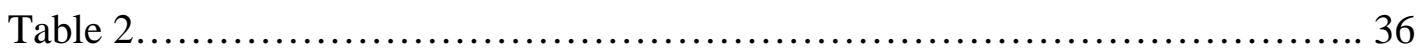

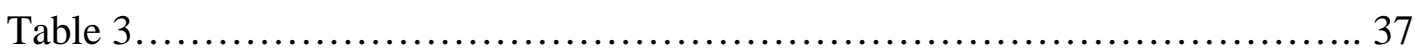




\section{Temporal trends in probabilistic maturation reaction norms and growth of}

\section{Atlantic cod (Gadus morhua L.) on the Icelandic shelf}

Heidi Pardoe ${ }^{1,2, *}$, Anssi Vainikka ${ }^{3}$, Gudmundur Thórdarson ${ }^{1}$, Gudrun Marteinsdóttir ${ }^{2}$, Mikko Heino $^{4,5,6}$

${ }^{1}$ Marine Research Institute, Skúlagata 4, PO Box 1390, 121 Reykjavik, Iceland

${ }^{2}$ Institute of Biology, University of Iceland, Sturlugata 7, 101 Reykjavik, Iceland

${ }^{3}$ Institute of Coastal Research, Swedish Board of Fisheries, Box 109, SE-742 22 Öregrund, Sweden

${ }^{4}$ Department of Biology, University of Bergen, Box 7800, N-5020 Bergen, Norway ${ }^{5}$ Institute of Marine Research, Box 1870 Nordnes, N-5817 Bergen, Norway

${ }^{6}$ Evolution and Ecology Program, International Institute for Applied Systems Analysis, A2361 Laxenburg, Austria

*Corresponding author. E-mail: heidi@hafro.is

Telephone/Fax: +354 5255426/+354 5752001

Author email addresses:

Anssi Vainikka: Anssi.vainikka@oulu.fi

Gudmundur Thordarson: gudthor@hafro.is

Gudrun Marteinsdóttir: runam@hi.is

Mikko Heino: mikko.heino@bio.uib.no 
Abstract: Decreasing temporal trends in probabilistic maturation reaction norm (PMRN) midpoints, symptomatic of earlier maturation despite environmentally induced variation in growth, have been observed in many exploited fish stocks. Here we studied the growth and maturation trends of female and male Icelandic cod (Gadus morhua) by estimating PMRNs for cohorts 1964 to 1999 , and found evidence that a shift towards maturation at smaller sizes and younger ages has occurred independently of changes in growth, condition and temperature. Weighting the data with regional survey abundance estimates to account for spatial heterogeneity in maturity status and sampling intensity did not qualitatively affect the temporal trends. Length-at-age also decreased through the study period which, through simulations, could be attributed to the energetic costs of earlier maturity at maturing age groups, but not at younger ages. These findings support the hypothesis that such changes in maturation schedules are not caused by environmental factors alone, but could also reflect a genetic change, potentially in response to intensive fishing.

Keywords: Atlantic cod; Iceland; Probabilistic maturation reaction norm; Phenotypic plasticity; Life history. 


\section{Introduction}

Trends towards maturation at younger ages and smaller sizes have been observed in many exploited fish stocks (e.g. Trippel 1995; Hutchings and Baum 2005; Jørgensen et al. 2007). Such changes are relevant for fisheries management since earlier maturation may have negative implications for population growth rates (reviewed by Hutchings and Fraser 2008) and yield (Law and Grey 1989; Stokes and Law 2000; Conover and Munch 2002) through decreased growth rates and size of fish in the catch (Heino 1998), and the reduced reproductive ability of a spawning stock comprised of smaller individuals and a higher proportion of first-time spawners (Marteinsdóttir and Begg 2002; Hutchings 2005). Shifts towards earlier maturity may also increase variability in population abundance (Stergiou 2002; Anderson et al. 2008; Stenseth and Rouyer 2008) and adversely affect the ability of a population to recover from overharvesting (Hutchings 2005; Walsh et al. 2006; Enberg et al. in press). Consequently, monitoring life-history traits and the potential causes of significant trends is essential for the effective long-term conservation and management of the resource (Trippel 1995; Jørgensen et al. 2007).

Phenotypic variability in the maturation pattern of a stock typically arises through plastic responses to environmental changes that may also be density-dependent. For example, relaxed competition for food in a fished-down stock may lead to accelerated growth and in turn earlier maturation (Trippel 1995; Law 2000). However, given that the maturation process is a complex physiological cascade, it is likely to be affected by ontogenetic processes related to not only growth, but environmental conditions and individual experience preceding, and at the point at which, the 'decision' to mature is made (see e.g. Wright 2007). Consequently, factors such as temperature (Dhillon and Fox 2004; Kraak 2007) and the status of energy reserves, reflected by condition (Yoneda and Wright 2005; Thorpe 2007), are potential proximate triggers of the maturation process (Wright 2007). However, these factors are often 
not taken into consideration when temporal trends in maturation patterns are studied (see however Grift et al. 2007; Mollet et al. 2007).

In addition to plastic responses, fishing has been identified as a potentially strong selective force in shaping the life-history traits of exploited fish populations (Law and Grey 1989; Conover and Munch 2002; Dunlop et al. in press). Harvest mortality may favour adaptations in traits such as size and age at maturation, growth rate, reproductive effort and behaviours related to feeding and mating, with changes being more pronounced when exploitation is size-selective (e.g. Heino and Godø 2002; Conover et al. 2005; Reznick and Ghalambor 2005). Aquaculture studies reporting moderate to high heritabilities for traits such as age at maturation and weight-at-age in $\operatorname{cod}\left(\mathrm{h}^{2}=0.12-0.56,0.20-0.51\right.$ respectively, Kolstad et al. 2006) and salmonids (Henryon et al. 2002; Kause et al. 2003) support the hypothesis that these traits are susceptible to genetic change, including that mediated through fishing.

The Icelandic stock of Atlantic cod (Gadus morhua) has supported an important fishery for decades (Fig.1a), although both the stock (Fig.1b) and catches have been below historic levels for many years (Anonymous 2007). Although no formal quantification is currently available, the fishery is considered to be highly size-selective, targeting large individuals (Anonymous 2007). Bottom trawling (conforming to codend mesh size regulations of $155 \mathrm{~mm}$ from 1977 and $135 \mathrm{~mm}$ for the past decade) provides the majority of the catch (Anonymous 2007). Icelandic cod become fully recruited to the fishery at age 5 or 6 , at which between approximately $25 \%$ and $55 \%$ are mature according to recent data (Anonymous 2007). Intensive exploitation during the last decades has led to truncation in the age structure of the stock (Marteinsdóttir and Thórarinsson 1998). Concurrently, declines in age and size at 50\% maturity have been observed (Marteinsdóttir and Begg 2002; Anonymous 2007). 
In this study, we assess trends in the maturation schedules of female and male Icelandic cod, between cohorts 1964 and 1999, utilising probabilistic maturation reaction norms (PMRNs) as our primary tool. We investigate whether there have been simultaneous trends in potential explanatory variables, namely water temperature or cod condition, or potential sampling biases related to the demographic effects of spatially segregated fishing or geographically differing cod characteristics, which would influence our interpretation of the PMRNs. We hypothesize that residual changes not explainable by environmental variables may be due to the effects of fishing, but note that a causal relationship cannot be demonstrated through such a descriptive study. We also introduce a novel method to examine whether changes in maturation could, through energetic trade-offs, explain those observed in length-atage, or whether independent changes could have occurred in growth.

\section{Materials and methods}

\section{Data}

Data were obtained from the Marine Research Institute (MRI), Iceland. All data were collected by bottom trawling, but originated from three sources: the annual spring (March) groundfish survey (GSD) which began in 1985, long-term ad-hoc research surveys (SD) and commercial catches (CD). The CD consisted of samples collected by observers from the Icelandic Directorate of Fisheries onboard commercial trawlers using 135 or $155 \mathrm{~mm}$ mesh size in the codend. GSD were collected using a bottom trawl with a $40 \mathrm{~mm}$ mesh size in the codend (Pálsson et al. 1989), and therefore only those SD collected with the same mesh size were selected. During MRI research surveys (SD, GSD) samples were taken randomly across the area of the continental shelf of Iceland occupied by cod, whereas the spatial coverage of CD was more limited (Fig. 2). For the purposes of our analysis, GSD and SD were considered comparable (see Discussion). PMRNs were estimated from $\mathrm{CD}$ so that they could be 
compared with PMRNs from SD/GSD, but were excluded from all trend analyses since CD are less representative.

For all data types, location and date were recorded, total length was measured to the nearest $1 \mathrm{~cm}$, otoliths were collected for age determination, sex was recorded and maturity stage (1: immature, 2: ripening, 3: spawning, 4: spent) was determined macroscopically according to the stages defined in Powles (1958). All fish were then reclassified as either juvenile (class 1) or mature (classes 2 - 4). From 1993, body, gutted and liver weights were also measured to the nearest $1 \mathrm{~g}$ during the annual spring groundfish survey (GSD). Cod in Icelandic waters spawn from late March to May/June (Marteinsdóttir et al. 2000) and therefore only those data collected between February and April were selected to maximise the likelihood of accurate maturity stage estimation and also to provide consistency between the different sources. The final dataset was divided into three temporally overlapping groups: 1) SD, years 1967 - 1984, 2) CD, years 1977 - 1995 and 3) GSD (with some SD), years 1989 2007 (Table 1, Fig. 2). To verify that combining data in the most recent time period was appropriate, temporal trends in PMRNs estimated from GSD alone and GSD combined with $\mathrm{SD}$ (GSD/SD) were compared using analysis of covariance (ANCOVA). For each age and sex combination, an ANCOVA explaining the Lp50 estimates (length at which the probability to mature is $50 \%$ ) as a function of data source (categorical variable, GSD or GSD/SD) and cohort (continuous variable), weighted by the inverse of the bootstrap variance (see below), was used to test for differences between the intercepts and slopes of the two Lp50 time series.

\section{Probabilistic maturation reaction norm (PMRN) estimation}

PMRNs describe age- and size-specific population level probabilities for an average individual to mature (Heino et al. 2002a). These maturation probabilities are thus conditional on an individual having attained a certain combination of age and size. Based on the assumption that a significant component of maturation plasticity results from 
environmentally-induced variation in growth and survival, and that these processes are the principle determinants of that age-size combination being reached, maturation reaction norms are considered to be largely unaffected by changes in average growth and mortality (Heino et al. 2002a; Dieckmann and Heino 2007; Heino and Dieckmann 2008). As it is not possible to separate first-time and repeat spawning Icelandic cod, retrospective PMRNs were estimated using the demographic method of Barot et al. (2004a) which relies on individual records of age $(a)$, size ( $s$, in this case length) and maturity status. PMRNs were estimated separately for males and females in each data group, and were determined for each age and cohort $(c)$ in three stages: estimation of 1) the maturity ogive o(a,s,c), 2) growth rate as the annual increment in average length $\Delta s$ and 3) the cohort-specific probability to mature at a certain age and size:

$$
p(a, s, c)=\frac{o(a, s, c)-o(a-1, s-\Delta s, c)}{1-o(a-1, s-\Delta s, c)}
$$

Temporal trends were visualised using PMRN midpoints (Lp50s), calculated by linear interpolation between the lengths associated with maturation probabilities immediately above and below 50\% (Barot et al. 2004b). Further details of these procedures, performed in $\mathrm{R}$ (version 2.6.0, R Foundation for Statistical Computing), are provided below. We focused our analyses on ages $4-8$, thus also requiring cod of age 3 for estimation of growth increments and maturity. In the majority of cases, the final age- and cohort-specific sample sizes (Table 1) fulfilled the minimum recommended sample size (100) for PMRN analysis (Barot et al. 2004a). However, for some ages and cohorts with very low sample sizes it was not possible to compute the Lp50.

The most important data requirement of the PMRN method is that proportions of mature fish within each age and length class are unbiased (Barot et al. 2004b). Differing 
sampling intensity between the northern and southern regions of Iceland could lead to a violation of this requirement because a significant proportion of the immature and mature cod are spatially segregated during the spawning season (Astthorsson et al. 1994; Marteinsdóttir et al. 2000; Begg and Marteinsdóttir 2003). Consequently, we considered weighting the proportions of mature and immature fish in our data with regional abundance estimates. This procedure makes the resulting estimates of population parameters less biased. Survey indices, estimates of the relative abundances of fish in the north and south (from the annual spring groundfish survey, Anonymous 2007), were available for data group 3 (cohorts 1985 - 1999) only. Those data (GSD/SD) were thus weighted by the age-, region- and year-specific survey index, divided by the corresponding age-, region- and year-specific sample size. ANCOVAs (see 'Data') were used to test for differences between temporal trends in Lp50s estimated from un-weighted and weighted (data source in ANCOVA models) data.

\section{Maturity ogives}

The proportions of mature fish as a function of age and size, i.e., maturity ogives, were estimated using logistic regression. Candidate models (including the cohort effect) were first examined using stepwise forward and backward selection procedures in SPSS (version 15.0.0, SPSS Inc. USA), allowing for all possible first-order interactions, with log-likelihood tests used to compare competing models. The final model was chosen based on the proportion of correctly classified observations and Nagelkerke's $\mathrm{R}^{2}$ (coefficient of determination for the logistic regression):

$$
\operatorname{logit}[o] \sim \text { age }+ \text { size }+ \text { factor }(\text { cohort })+\text { age } \times \text { factor }(\text { cohort })+\text { size } \times \text { factor }(\text { cohort })
$$

where size refers to length in $\mathrm{cm}$. Age was entered as a continuous variable since the agespecific sample sizes were sometimes too low to allow full factorial estimation of the effects. 
The predictive power of the chosen model was similar to that in which age was factorial, but AIC (Akaike information criterion) was lower. The age $\times$ length interaction was omitted since its inclusion caused 'swapping' in the reaction norm, i.e., in some samples the probability to mature was higher at smaller sizes, likely an artefact of low sample sizes (Barot et al. 2004a).

\section{Growth}

Age- and cohort-specific growth increments were estimated by 1) predicting average length at age $a$ in year $y$ using the model:

$$
\text { size } \sim \text { age }+ \text { factor(year) }+ \text { age } \times \text { factor }(\text { year })
$$

and then 2) calculating the difference between estimated lengths at age $a$ in year $y$ and at age $a-1$ in $y-1$. A linear effect of age was chosen because of insufficient data in some samples for full factorial estimation of the effects, and for consistency with the ogive estimation.

\section{Confidence intervals}

Since obtaining direct estimates of the error associated with the reaction norm midpoints is beyond realistic options (Barot et al. 2004a), the PMRN estimation procedure was repeated 1000 times by year stratified bootstrapping of the original data. Confidence intervals (CI) were estimated as the 2.5 and 97.5 percentiles of the 1000 bootstrapped Lp50 estimates for each age and cohort. Low sample sizes in the re-sampled data, particularly for those ages where few individuals mature, can result in wide CI for the Lp50s or even make it impossible to compute the PMRN for those bootstrap samples (Barot et al. 2004a). If Lp50s were not successfully calculated in $\geq 90 \%$ of the 1000 bootstrap samples, that age/cohort was removed from further analyses.

\section{Analysis of trend and sex differences}


To test for an age-specific trend in Lp50s between cohorts 1964 and 1999, the reaction norm midpoints were regressed against cohort (as a continuous variable) and weighted by the inverse of the bootstrap variance (Grift et al. 2003).

To determine whether males and females have different PMRNs we used a randomization test (Barot et al. 2004b). Observed sex values were redistributed randomly across the data set and age- and cohort-specific Lp50s were estimated from these new data, for each sex separately, using the method described above. These Lp50s were modelled as a function of age, cohort and sex (all considered as factors) and the parameter corresponding to the effect of sex was recorded. The randomization procedure was repeated 1000 times, separately for each data group. The same parameter was collected for the original, nonrandomized, data sets. The effect of sex was then considered to be significant if this parameter estimate fell within or beyond the upper $5 \%$ (one-tailed test: $\mathrm{H}_{1}$ being females have higher PMRNs than males) tail of the distribution of the 1000 coefficients obtained from the randomization procedure.

\section{Potential explanatory variables of Lp50 trends}

In principle, fishing in northern Icelandic waters where immature cod are located in greatest abundance (Astthorsson et al. 1994) could result in their selective removal, particularly during the spawning season (Thórarinsson and Jóhannesson 1997; Begg and Marteinsdóttir 2003), and thus lead to a sampling bias towards mature cod (at each size and age class) in research data. Fishing might then cause false trends in the estimated Lp50s, simply as an artefact of sampling, particularly if this bias increased through time. To address this, we investigated potential correlations between fishing mortality $\left(\mathrm{F}\right.$, year $\left.{ }^{-1}\right)$ and age- and sex-specific PMRN midpoints using linear regressions weighted by the inverse of the bootstrap variance. $\mathrm{F}$ was available as both 1) average annual mortality of ages $5-10$ (F(5-10), Fig. 1a) and 2) age- and cohort-specific estimates (Anonymous 2007). 
Factors such as condition and temperature could also directly affect maturation decisions and thereby explain changes in PMRNs (Kraak 2007; Marshall and McAdam 2007; Thorpe 2007). Average condition, represented by the hepatosomatic (HSI, \%) and relative body condition $(\mathrm{Kr})$ indices, was calculated from GSD separately for immature and mature Icelandic cod aged $4-8$ years in the spring of $1993-2007$, using the method described in Pardoe et al. (2008). Because of the potential error associated with assignment of maturity status in the autumn, immature and mature cod were combined before estimating these indices from MRI autumn (October) groundfish survey data for the period 1995 - 2007.

Temperature $\left({ }^{\circ} \mathrm{C}\right)$ time series' collected by MRI on the main spawning grounds in the southwest (Selvogsbanki) and off the central north coast (Siglunes) were used to 1) qualitatively assess if Lp50 trends reflected those observed in temperature and 2) quantitatively examine correlations between Lp50s and average temperature. For the former, annual temperature measurements made at $50-150 \mathrm{~m}$ in February/March were deemed most representative of the long-term conditions in Icelandic waters (H. Valdimarsson, MRI, Skúlagata 4, 121 Reykjavik, Iceland, personal communication, 2008). For the latter, measurements from the $3^{\text {rd }}$ quarter, when temperature might be expected to directly influence the maturation decision of cod which will spawn in the following spring, were available for the majority of years between $1968-2007$ (north, $50-150 \mathrm{~m}$ ) and $1971-2007$ (southwest, 0 - $200 \mathrm{~m})$. Correlations were investigated according to Kraak (2007) with the exception that the positive trends in temperature (north: $\mathrm{P}=0.0039$, southwest: $\mathrm{P}=0.001$ ) were removed prior to the analyses. This was necessary since temporal covariation between trends in Lp50s and temperature would otherwise confound these analyses. Linear regression (weighted by the inverse of the bootstrap variance) was used to test for an effect of detrended temperature measured one $\left(t_{\text {year-1 }}\right)$, two $\left(t_{\text {year-2 }}\right)$ and three $\left(t_{\text {year- }-3}\right)$ years prior to the assessment of maturity status $\left(\mathrm{t}_{\mathrm{year}}\right)$ on the Lp50 trends. 


\section{Growth trends}

Trends in average length were investigated using a GLM which included 1) the main effect of age, 2) first-order interactions between age and cohort; cohort and sex; cohort and maturity; cohort and region (south or north); cohort and data group (SD or GSD/SD); age and region; age and maturity; age and data group; age and sex; maturity and region; maturity and data group, and 3) second order interactions between cohort, age and maturity; cohort, age and data group. All variables were factorial with the exception of cohort. The model was based primarily on those effects and interactions considered to be biologically meaningful, although the final model also had the lowest AIC out of all those examined.

\section{Effect of earlier maturation on growth}

Due to the allocation of limited energy to reproduction, maturation usually leads to slower growth (Roff 1983; Lester et al. 2004; Heino et al. 2008). In order to investigate the relationship between the observed lengths-at-age and maturation schedules, we simulated cohorts of 100000 individuals which matured according to the results of our PMRN analyses and grew according to the Lester et al. (2004) fixed investment model. The model was parameterised for Icelandic cod by first estimating the average gonadosomatic index (GSI, $11.0 \%$ and $7.5 \%$ for males and females respectively) from GSD combined for all ages (4-8 years), for the period 1994 - 2007, and then converting this to an energetic GSI (average GSI $\times 1.73$, yielding $19.0 \%$ and $13.0 \%$ for males and females respectively; Lester et al. 2004). Juvenile growth rates matching the GSIs and observed lengths-at-age were then found using the least squares method $\left(11.5 \mathrm{~cm} \cdot \mathrm{year}^{-1}\right.$ and $11.6 \mathrm{~cm} \cdot y e a r^{-1}$ for males and females respectively). The lengths-at-age used in the fitting were averages of the whole time period (cohorts 1964 - 1999), estimated from SD/GSD. In addition, a value of 30\%, representing a 'high' energetic GSI and corresponding to juvenile growth increments of $11.7 \mathrm{~cm} \cdot y^{-1}{ }^{-1}$ and $11.9 \mathrm{~cm} \cdot$ year $^{-1}$ for males and females respectively, was used to estimate the upper limits of the 
predicted change in growth. Sex-specific maturation probabilities at age ( $4-8$ years) and at a

250 fixed length (average lengths-at-age described above) were derived from the PMRN analysis of GSD/SD. On completion of the simulation, the average lengths-at-age of all individuals (regardless of maturity status) were calculated, and linear regressions were used to estimate the average age-specific change between cohorts 1964 and 1999. These predicted changes were compared to those resulting from linear regression, weighted by the cohort and agespecific sample sizes, of the average lengths-at-age estimated for the PMRN analyses (eqn. 3). There was no mortality in the simulation.

\section{Results}

\section{Length-at-age}

Short-term fluctuations in average length (estimated using eqn. 3) were generally similar across all ages and sexes (Fig. 3). For those cohorts where both GSD/SD and CD were

261 available, average length-at-age from $\mathrm{CD}$, in comparison to GSD/SD, tended to be higher for the youngest ages but smaller for the oldest ages (Fig. 3). A number of trends in average length were revealed (see Methods 'Growth trends' section, Fig. 4): all of the modelled interactions were significant (along with the main effect of age) $(\mathrm{P}<0.001)$. Notably though, average length of Icelandic cod had decreased during the study period (Fig. 4).

\section{Probabilistic maturation reaction norms}

We first evaluated the influence of data source (GSD or GSD/SD, un-weighted or weighted GSD/SD) on the PMRN estimates in the most recent time period (cohorts 1985 - 1999). For the majority of age/sex combinations, temporal trends in Lp50s estimated from GSD only and GSD/SD did not differ (ANCOVA, $\mathrm{P}=0.11-0.91$ ). The only exceptions were age 4 and 5 males, for which there were significant differences in the intercepts $(\mathrm{P}=0.031$ and $\mathrm{P}=0.027$ respectively) and slopes $(\mathrm{P}=0.033$ and $\mathrm{P}=0.027$ respectively) of the regression lines. 
However after Bonferroni correction these too would have been non-significant $(\mathrm{P}>0.05)$. It was therefore deemed appropriate to combine GSD and SD in this time period.

Comparison of PMRNs based on un-weighted and weighted (see Methods) GSD/SD showed that weighting produced visually higher PMRN midpoints for most age and cohort combinations (Fig. 5). However, ANCOVAs did not reveal any differences between the intercepts or slopes of the weighted and un-weighted Lp50 time series $(P=0.10-0.84)$. It was therefore concluded that using un-weighted data in all subsequent analyses was acceptable.

The negative slopes of the maturation reaction norms (Fig. 6) signify that the length at which Icelandic cod attains a certain probability to mature decreases with age. A significant downward trend in the reaction norm slopes (i.e. they had become more negative) was found for female ( $\mathrm{P}=0.032)$, but not male $(\mathrm{P}=0.7)$ cod, indicating that the effect of age on female maturation probabilities had increased over time. PMRNs based on research survey data (SD, GSD/SD) showed that recent cohorts of Icelandic cod attained maturity at a smaller size than those of the early 1970s (Fig. 6).

These downward trends are evident in the time series' of cohort-specific Lp50s, despite short-term variation in the midpoints at all ages, and wide CI for many age and cohort combinations (Fig. 7). Short-term fluctuations in the Lp50s could not be attributed to any biological anomalies in the data, but most likely reflect 'noise' in the data (see Discussion). Significant estimates for the decrease in Lp50 between cohorts 1964 and 1999 varied between $6.2 \mathrm{~cm}$ and $14.3 \mathrm{~cm}$ for females and $6.4 \mathrm{~cm}$ and $12.9 \mathrm{~cm}$ for males (Table 2). For age 7 female and male Icelandic cod, this corresponds to a decrease of 0.23 and $0.27 \mathrm{~cm} \cdot \mathrm{year}^{-1}$, or 0.33 and $0.44 \%$ year $^{-1}$, respectively (Table 2). There was no significant trend in the Lp50s of age 4 and 5 females (Table 2). Lp50 estimates from CD tended to be higher than those from SD and 
GSD/SD, and the majority were either associated with large CI (Figs. 6\&7) or excluded (and therefore not shown) due to data limitations.

Randomization tests revealed differences in the Lp50s of male and female cod: nonrandomized parameter estimates for the effect of sex fell within and beyond (SD, cohorts 1964 - 1976 and GSD/SD, cohorts 1985 - 1999 respectively) the upper 5\% tail of the distribution of the 1000 coefficients obtained from the randomization procedure, indicating that females attain 50\% maturation probability at a significantly larger size than males.

\section{Potential variables explaining trends in PMRNs}

Spatial heterogeneity in fishing could lead to a sampling bias towards mature Icelandic cod in research data, and therefore underestimation of PMRN midpoints. Furthermore, a positive trend in this bias through time could explain the decrease in Lp50s. However, no relationships between Lp50s and fishing mortality F of cod aged $4-6$ years were observed, and for cod aged 7 and 8 years relationships were in fact weakly positive. For age 8 females, the correlation between Lp50 and $\mathrm{F}(5-10)$ was significant $\left(\mathrm{P}=0.045, \mathrm{R}^{2}=0.178\right)$, as was that with age- and cohort-specific $\mathrm{F}\left(\mathrm{P}=0.019, \mathrm{R}^{2}=0.24\right)$.

As changes in PMRNs could also result from the direct influence of environmental factors on the maturation process, we examined trends in average condition of Icelandic cod and temperature of Icelandic waters. An overall decline in condition, measured as HSI and Kr, of immature and mature cod was present between 1993 and 2007 (Fig. 8). This trend is the opposite of that which would explain the facilitated maturation illustrated by the PMRNs. Temperature southwest and north of Iceland varied notably between years. However, prior to 1995 there was an overall decrease in average temperature, a trend that has since reversed markedly (Fig. 8). No significant relationships between de-trended temperature (southwest and north of Iceland, in the $3^{\text {rd }}$ quarter of $t_{\text {year- } 1,}, t_{\text {year-2 }}$ or $\left.t_{\text {year-3 } 3}\right)$ and PMRN mid-points $\left(t_{\text {year }}\right)$ were found $(\mathrm{P}>0.05)$. 


\section{Effect of earlier maturation on growth}

Simulations to investigate the influence of earlier maturation, as predicted by the PMRN analyses, on average length-at-age revealed that this would have greatest effect in the oldest age groups. For those ages, the observed shift in maturation probability was predicted to result in a decrease in average length of as much as $3.8 \mathrm{~cm}$ when the average GSI was converted to an energetic GSI; at ages 7 and 8 the predicted changes in average length were comparable to those observed (Table 3). When a 'high' energetic GSI value of 30\% was assumed, average length declined even more (Table 3). However, even for the high GSI, earlier maturation could not fully account for the observed declines at the youngest ages.

\section{Discussion}

In this study, we found that the size at $50 \%$ maturation probability of female and male Icelandic cod had decreased between the 1964 and 1999 cohorts. The corresponding maturation probabilities at a fixed length (the average length of cod at a certain age) had increased: for example for cod of age 6 years, the probability to mature had risen from $16 \%$ to $44 \%$ and from $29 \%$ to $53 \%$ for females of $71 \mathrm{~cm}$ and males of $70 \mathrm{~cm}$ respectively. The observed PMRN trends could not be explained by those in water temperature or fish condition, which have been proposed as alternative explanations for previously published PMRN trends (e.g. Kraak 2007; Marshall and McAdam 2007; Wright 2007). We also found no support for the hypothesised effects of potential sampling biases related to spatial variation in fishing and maturity. Furthermore, we demonstrated that the observed declines in average length of mature age groups could result from the long-term shifts towards earlier maturation.

Although we have made significant progress in our quest to establish how and why maturation in the Icelandic cod stock has changed, the relative contributions of residual phenotypic plasticity and alterations to the genetic composition of the stock cannot be determined from this correlative study alone (Marshall and Browman 2007; Dieckmann and 
Heino 2007; Browman et al. 2008). Because age and size are only proxies of the physiological factors that trigger maturation (Marshall and Browman 2007), PMRNs cannot provide a description of maturation tendency that is immune to environmental influences. Indeed, there is ample evidence that age- and size-based PMRNs are influenced by the environment (e.g. Heino et al. 2002b; Law 2007), including residual growth-related effects (Morita and Fukuwaka 2006). While we have failed to identify environmental influences that could explain the PMRN trends in our study, absence of evidence is no proof of absence. Nevertheless, it seems unlikely that the large changes identified in this study, and in several other studies, could be fully ascribed to some important but yet unidentified change in the environment. At the same time, life-history theory predicts that increased mortality, particularly the size-selective mortality associated with commercial fishing, will bring about evolutionary change in maturation schedules (Stearns 1992; Law 2000). Accordingly, this has been proposed as the most parsimonious explanation for comparable PMRN trends in a number of exploited stocks (Jørgensen et al. 2007; Heino and Dieckmann 2008). Clearly no definitive conclusions can be made in the absence of genetic evidence, and until those genes that code for maturation are identified, and genotypic and phenotypic correlations are understood, that task remains elusive (Kuparinen and Merilä 2008; Naish and Hard 2008). In order to assess whether fishing could have caused our observed trends, the predicted rates of change should be quantitatively compared to estimates of selection differentials generated by fishing (Law 2007; Swain et al. 2007). This is beyond the scope of the current study, although eco-genetic models developed for cod-like populations suggest that fishing is capable of driving fast evolution in PMRNs (Dunlop et al. in press; Enberg et al. in press).

Alongside maturation schedules, there are potential implications of intensive sizeselective harvesting for individual growth rates in exploited fish stocks (Ricker 1981; Sinclair et al. 2002; Swain et al. 2007). Because variation in growth is partially environmentally 
driven and partially genetic (Imsland and Jonassen 2001; Conover and Munch 2002; Kolstad et al. 2006), fishing could invoke both phenotypically plastic and evolutionary responses in this trait. PMRN trends paralleled by a trend in growth might therefore implicate a genetic shift in one or both of these traits if they are linked by sufficiently strong genetic covariance (Dieckmann and Heino 2007). In a recent study of southern Gulf of St. Lawrence cod, Swain et al. (2007) found evidence of a genetic response, in the form of slower growth, to selection on body size. However, reduced growth rates could also reflect confounded changes in the maturation schedule or reproductive investment because of energetic trade-offs (Heino et al. 2008). In an attempt to address this issue, we ran a simple simulation to investigate what effect the observed changes in maturation might have on average length of Icelandic cod, according to the Lester et al. (2004) growth model. This exercise suggested that the declines in growth detected in the present study could be explained by the energetic costs of earlier maturation in the older, mostly mature, age groups only. For the younger juvenile ages, without reproductive costs, earlier maturation could not account for the observed decreases. Whether the observed declines in growth of Icelandic cod, particularly in the younger age groups, are purely phenotypic or also have a genetic component, therefore remains unresolved. However, our method provides a tool which could be combined with that of Swain et al. (2007) in order to investigate the propensity for direct selection on growth rates in this, and other, fish stocks.

To facilitate comparison to other cod studies utilising PMRNs, we quantified the magnitude and rate of the reduction in the PMRN midpoints of Icelandic cod over 36 cohorts, following the methodology of Jørgensen et al. (2007, see their Table S2). We estimated the total change to be $8-20 \%$ (average: $13 \%$ ) and the rate as $2.2-6.3 \times 10^{3}$ darwins (average 3.8 $\mathrm{x} 10^{3}$ darwins). This suggests that the magnitude and rate of change in the maturation schedule of Icelandic cod is comparable to that observed in other stocks of Atlantic cod (e.g. 
Heino et al. 2002b; Barot et al. 2004b; Olsen et al. 2005). However, it is interesting to note that for the latest maturing stocks, Icelandic cod and Northeast Arctic cod (Trippel 1995; Anonymous 2007), this change has been relatively small; the magnitude of change over 67 cohorts was calculated to be $12 \%$, at a rate of $2.1 \times 10^{3}$ darwins for Northeast Arctic cod (Jørgensen et al. 2007).

Female Icelandic cod were found to reach $50 \%$ maturation probability at a larger size than males, indicating that sex differences in age- and length-based maturity ogives (Marteinsdóttir and Begg 2002) are not the result of variation in growth or survival alone. Similar sex differences have been found in other cod stocks such as those off Labrador and Newfoundland (Olsen et al. 2005). In contrast, variation between the sexes of Georges Bank and Gulf of Maine cod only existed at ages 2 and 3 respectively, and in these cases females had a marginally higher tendency to mature at a given age and size than males (Barot et al. 2004b).

The estimation of PMRNs through the demographic method (Barot et al. 2004a), as it is usually applied, relies on two simplifying assumptions: that both growth and survival are, within an age group, independent of maturity status and size. The method has been shown to be robust to moderate violations of these assumptions however (Barot et al. 2004a). Unfortunately, we are unaware of any available empirical evidence which would either attest or refute similar growth rates of immature and mature Icelandic cod, or size-independent growth, within an age class. However, it is possible that differences exist between the survival of immature and mature Icelandic cod within an age class. Fishing in northern Icelandic waters, particularly during the spawning season, could result in the selective removal of immature cod (Thórarinsson and Jóhannesson 1997), and therefore lead to a sampling bias towards mature cod in research data. In the present study, Lp50s estimated from commercial data $(C D)$ would suggest that the fishery is immature biased. However, the CD originate from 
bottom trawling during a select few months and so are unlikely to be representative of the Icelandic cod fishery as a whole. This is even more apparent when the contribution of gears such as gillnets and longlines, which target the mature component of the stock, to mean fishing mortality and the total catch is considered (Begg and Marteinsdóttir 2003; Anonymous 2007). The positive correlations observed between fishing mortality and Lp50s of the older ages is in agreement with this last statement, and thereby supports the hypothesis that the observed decreasing trends were not simply artefacts of sampling.

Our analyses were based on three data groups, corresponding to three overlapping time periods. Potential sources of error or bias existed in the $\mathrm{CD}$ as reliability of the maturity classifications is somewhat debatable (S. Schopka, MRI, Skúlagata 4, 121 Reykjavik, Iceland, personal communication, 2008), and these data were collected in a limited area of the Icelandic shelf, with larger meshes. However, by selecting data from one gear type and a restricted period of the year, we were able to minimise variation between the data groups. Despite this, we excluded CD Lp50 estimates from our trend analyses. Consequently, we were able to compare PMRN and growth analyses of research and commercial data, while avoiding any misleading influence of $\mathrm{CD}$ on our results. In doing so, we found quite notable differences in our estimates from the two data types (compare the grey and black lines/points in Figures 3, 6 and 7). Inconsistency between groundfish survey data (GSD) and other research survey data (SD), particularly those SD collected early in the time series, was also a possibility because of discrepancies in sampling design and intensity. Despite this, preliminary exploration of the data did not reveal anything obviously problematic for the analyses, and we were careful that our data selection only minimised this variation, and not that which might be biologically meaningful. We therefore do not consider this to have significantly influenced our findings. Furthermore, the observed short-term variability in the Lp50s does not alter our conclusion of an overall downward trend in the PMRNs of Icelandic 
cod. Instead such fluctuations, which are often observed (see e.g. Olsen et al. 2005; Mollet et al. 2007; Vainikka et al. 2009), are to be expected given that there will be plastic effects that have not been accounted for, for example originating from the short-term variation in temperature and condition. Some residual noise is also unavoidable, due to small sample sizes, measurement errors and variable sampling (Heino and Dieckmann 2008).

Temperature in Icelandic waters has increased since 1995, however no corresponding changes in reaction norm midpoints were observed. Furthermore, no correlative relationships between Lp50s and temperature were detected. It is therefore unlikely that temperature has made a consistent contribution to the changes in maturation. As a cautionary note, although these temperature time series' are thought to represent average conditions in Icelandic waters, individual cod may still experience different ambient temperatures at the time relevant for the maturation decision.

There was a general decline in condition of Icelandic cod in the period since 1993. Since good condition is assumed to promote earlier maturation (Marshall and McAdam 2007), the opposite trend would have led us to suspect some influence of condition on the observed shift towards earlier maturation. As weight data are lacking prior to 1993, no conclusive statements can be made regarding the role of condition in the observed maturation trends. However, it is unlikely that changes in condition are responsible for the overall downward trend in maturation, although it is feasible that short-term variation in condition (Pardoe et al. 2008) may have contributed to the observed variability in Lp50s. In four previous PMRN studies, of plaice (Pleuronectes platessa, Grift et al. 2007), sole (Solea solea, Mollet et al. 2007), and Atlantic cod in the Baltic (Vainikka et al. 2009) and off Newfoundland (Baulier et al. 2006), inclusion of condition as a third explanatory variable of maturation probability did not alter the conclusion of a decreasing temporal trend in the PMRN midpoints. For cod, the major storage location of lipids is the liver (Eliassen and Vahl 1982a; Holdway and Beamish 
1984) and so HSI is an obvious candidate for three-dimensional PMRN studies of this species. However, mature cod have been found to have higher liver condition than immature cod (Eliassen and Vahl 1982b; Vitale et al. 2006; Pardoe et al. 2008), suggesting that better condition may be the consequence, rather than cause, of maturation (Rijnsdorp 1990). If this is the case, it could mean the false interpretation of a positive effect of condition on maturation probability (Grift et al. 2007), and should therefore be considered in future experimental investigations.

The influence of social factors on maturation cannot be determined from this study as accounting for such effects is practically impossible with the available data. If maturation of subordinate juvenile cod is suppressed by the presence of dominant adults, as has been found in other, admittedly more sedentary, fish species (e.g. Fricke and Fricke 1977; Borowsky 1978; Jones and Thompson 1980), truncation in the age structure of Icelandic cod (Marteinsdóttir and Thórarinsson 1998) could account for some of the observed PMRN changes. Furthermore, changes in the density and size structure of the stock are directly related to fishing mortality, i.e., selection, and it therefore becomes impossible to disentangle the direct within-cohort effects of fishing (viability selection) from potentially evolutionary factors (truly inherited changes).

Phenotypic (Marteinsdóttir and Begg 2002; Jónsdóttir et al. 2006; Pardoe et al. 2008), and more recently genetic (Pampoulie et al. 2006) and behavioural (Pálsson and Thorsteinsson 2003; Pampoulie et al. 2008; V. Thorsteinsson, MRI, Skúlagata 4, 121 Reykjavik, Iceland, unpublished data), structure within the Icelandic cod stock has been detected. Most prominent is the variation in life-history traits between the northern and southern regions, with cod in the former maturing at older ages and larger sizes than their conspecifics in the south (Jónsson 1954; Marteinsdóttir and Begg 2002). In addition, the stock structure is temporally variable. A significant proportion of the mature stock migrates 
between the main feeding and spawning grounds in the northwest and southwest, respectively, and is contrasted by seemingly resident behaviour of other stock components (Jónsson 1954; Pampoulie et al. 2006). Consequently, variation in sampling intensity between the regions, or even on a finer spatial scale, could introduce biases to analyses such as those performed in the present study. In order to address this, we weighted data from the most recent time period with available regional estimates of stock abundance, in such a way that observations from the more poorly sampled (and immature-dominated) northern region had greater weight. As long as it is reasonable to assume that this bias has remained approximately constant, this weighting would not appear essential for the evaluation of a temporal trend in the trait of interest, illustrated by comparison of the weighted and un-weighted Lp50 time series. Instead, this method's value is apparent for the estimation of the position and form of the actual PMRN.

Icelandic cod is not an exception: spatial population structure has been detected in a large number of commercial fish stocks (e.g. Hutchinson et al. 2001; Knutsen et al. 2003; Ruzzante et al. 2006). The accurate detection of persistent changes in life-history traits within such stocks would therefore appear dependent on our capacity to disaggregate such trends between relevant stock components, or even behavioural types (Biro and Post 2008). But why do we consider this important? Firstly, there is the possibility that divergent life-history responses to environmental change or selective pressures will emerge within these components, and these may go undetected, or lead to erroneous conclusions, when studies are performed at an inappropriate spatial resolution. Secondly, replacement of one depleted population by another (Hutchinson et al. 2003) could feasibly be interpreted as a phenotypic or evolutionary shift in the life-history tactic of the stock, or dominant sub-component. It is therefore important to bear in mind that if any of the aforementioned cases apply to the Icelandic cod stock, or indeed if there are population components that are genetically distinct 
in their maturation properties, our stock-level PMRN analyses, along with the weighting method, would be inappropriate and perhaps misleading. Unfortunately, phenotypic and in particular behavioural and genetic complexity in the Icelandic cod stock is still poorly understood. Consequently, in light of what is known and the data that are available, we have to assume that our analyses are appropriate. We therefore encourage future investigation of the potential implications of stock complexity, both genetic and phenotypic, for the detection of directional responses to natural or anthropogenic environmental change.

We have detected declining trends in age and size at maturation of Icelandic cod which could not be explained by demographic effects, variation in phenotypic growth, characteristics of the environment represented by ambient temperature and average condition, or sampling biases. Regardless of its origin, earlier maturation may have negative implications for the biological and commercial productivity of the stock (e.g. Heino 1998; Stokes and Law 2000; Stenseth and Rouyer 2008). Furthermore, reversal of any genetic change is predicted to be slow, or even unachievable, because of relatively weak natural selection pressures (Law 2000; Enberg et al. in press). On a more positive note, the ability to adapt to a changing environment, in this case through the age and size at which Atlantic cod mature, could be regarded in a positive light if we consider it as a buffer against stock collapse. Nevertheless, our findings call for a comprehensive monitoring scheme of spatial and temporal variation in maturation and other life-history traits, along with a retrospective and prospective investigation of the propensity for fisheries-induced evolution within the stock, based on past and future exploitation patterns and management strategies.

\section{Acknowledgements}

We thank Loïc Baulier, Tim Grabowski, Richard Law, Bruce McAdam, Fabian Mollet, Davnah Urbach and Héðinn Valdimarsson, along with two anonymous referees and the journal's editorial team, for their valuable input and comments which enabled us to greatly 
improve the manuscript. We also thank the scientists and crews at the Marine Research Institute who were involved in the sampling and preparation of the data used in this study. This research was supported by the European Marie Curie Research Training Network FishACE (Fisheries induced Adaptive Changes in Exploited Stocks, Contract MRTN-CT2004-005578), and the Specific Targeted Research Project Fisheries-induced Evolution (FinE, contract number SSP-2006-044276), funded through the European Community's Sixth Framework Programme. The support of the Marine Research Institute, the Icelandic Centre for Research and the Bergen Research Foundation is gratefully acknowledged.

\section{References}

Anderson, C.N.K., Hsieh, C., Sandin, S.A., Hewitt, R., Hollowed, A., Beddington, J., May, R.M., and Sugihara, G. 2008. Why fishing magnifies fluctuations in fish abundance. Nature 452: 835-839. doi:10.1038/nature06851.

Anonymous, 2007. Report of the ICES North-western Working Group (NWWG). ICES CM 2007/ACFM:17.

Astthorsson, O.S., Gislason, A., and Gudmundsdóttir, A. 1994. Distribution, abundance, and length of pelagic juvenile cod in Icelandic waters in relation to environmental conditions. ICES Mar. Sci. Symp. 198: 529-541.

Barot, S., Heino, M., O’Brien, L., and Dieckmann, U. 2004a. Estimating reaction norms for age and size at maturation when age at first reproduction is unknown. Evol. Ecol. Res. 6: $659-678$.

Barot, S., Heino, M., O’Brien, L., and Dieckmann, U. 2004b. Long-term trend in the maturation reaction norm of two cod stocks. Ecol. Appl. 14: 1257-1271.

Baulier, L., Heino, M., Lilly, G.R., and Dieckmann, U. 2006. Body condition and evolution of maturation of Atlantic cod in Newfoundland. ICES CM 2006/H:19. 
Begg, G.A., and Marteinsdóttir, G. 2003. Spatial partitioning of relative fishing mortality and spawning stock biomass of Icelandic cod. Fish. Res. 59: 343-362.

Biro, P. A., and Post, J. R. 2008. Rapid depletion of genotypes with fast growth and bold personality traits from harvested fish populations. Proc. Natl. Acad. Sci. USA 105: 2919-2922. doi:10.1073/pnas.0708159105.

Borowsky, R. 1978. Social inhibition of maturation in natural populations of Xiphophorus variatus (Pisces: Poeciliidae). Science 201: 933-935.

Browman, H.I., Law, R., and Marshall, T. 2008. The role of fisheries-induced evolution. Science 320: 47.

Conover, D.O., and Munch, S.B. 2002. Sustaining fisheries yields over evolutionary time scales. Science 297: 94-96.

Conover, D.O., Arnott, S.A., Walsh, M.R., and Munch, S.B. 2005. Darwinian fishery science: lessons from the Atlantic silverside (Menidia menidia). Can. J. Fish. Aquat. Sci. 62: 730-737. doi:10.1139/F05-069.

Dhillon, R.S., and Fox, M.G. 2004. Growth-independent effects of temperature on age and size at maturity in Japanese medaka (Oryzias latipes). Copeia 2004: 37-45

Dieckmann, U., and Heino, M. 2007. Probabilistic maturation reaction norms: their history, strengths, and limitations. Mar. Ecol. Prog. Ser. 335: 253-269.

Dunlop, E.S., Heino, M., and Dieckmann, U. In press. Eco-genetic modeling of contemporary life-history evolution. Ecol. Appl.

Eliassen, J-E., and Vahl, O. 1982a. Seasonal variations in the gonad size and the protein and water content of cod, Gadus morhua (L.), muscle from northern Norway. J. Fish Biol. 20: $527-533$. 
Eliassen, J-E., and Vahl, O. 1982b. Seasonal variations in biochemical composition and energy content of liver, gonad and muscle of mature and immature cod, Gadus morhua (L.) from Balsfjorden, northern Norway. J. Fish Biol. 20: 707-716.

Enberg, K., Jørgensen, C., Dunlop, E.S., Heino, M., and Dieckmann, U. In press. Implications of fisheries-induced evolution for stock rebuilding and recovery. Evol. Appl.

Fricke, H., and Fricke, S. 1977. Monogamy and sex change by aggressive dominance in coral reef fish. Nature 266: 830-832.

Grift, R.E., Rijnsdorp, A.D., Barot, S., Heino, M., and Dieckmann, U. 2003. Fisheriesinduced trends in reaction norms for maturation in North Sea plaice. Mar. Ecol. Prog. Ser. 257: $247-257$.

Grift, R.E., Heino, M., Rijnsdorp, A.D., Kraak, S.B.M., and Dieckmann, U. 2007. Threedimensional maturation reaction norms for North Sea plaice. Mar. Ecol. Prog. Ser. 334: $213-224$.

Heino, M. 1998. Management of evolving fish stocks. Can. J. Fish. Aquat. Sci. 55: 1971-1982.

Heino, M., and Dieckmann, U. 2008. Detecting fisheries-induced life-history evolution: An overview of the reaction-norm approach. Bull. Mar. Sci. 83: 69-93.

Heino, M., and Godø, O.R. 2002. Fisheries-induced selection pressures in the context of sustainable fisheries. Bull. Mar. Sci. 70: 639-656.

Heino, M., Dieckmann, U., and Godø, O.R. 2002a. Measuring probabilistic reaction norms for age and size at maturation. Evolution 56: 669-678.

Heino, M., Dieckmann, U., and Godø, O.R. 2002b. Reaction norm analysis of fisheriesinduced adaptive change and the case of the Northeast Arctic cod. ICES CM 2002/Y:14. 
Heino, M., Baulier, L., Boukal, D. S., Dunlop, E. S., Eliassen, S., Enberg, K., Jørgensen, C., and Varpe, Ø. 2008. Evolution of growth in Gulf of St Lawrence cod? Proc. R. Soc. Lond. B 275: 1111-1112. doi:10.1098/rspb.2007.1429.

Henryon, M., Jokumsen, A., Berg, P., Lund, I., Pedersen, P.B., Olesen, N.J., and Slierendrecht, W.J. 2002. Genetic variation for growth rate, feed conversion efficiency, and disease resistance exists within a farmed population of rainbow trout. Aquaculture 209: $59-76$.

Holdway, D.A., and Beamish, F.W.H. 1984. Specific growth rate and proximate body composition of Atlantic cod (Gadus morhua L.). J. Exp. Mar. Biol. Ecol. 81: 147-170.

Hutchings, J. 2005. Life history consequences of overexploitation to population recovery in Northwest Atlantic cod (Gadus morhua). Can. J. Fish. Aquat. Sci. 62: 824-832. doi:10.1139/F05-081.

Hutchings, J.A., and Baum, J. 2005. Measuring marine fish biodiversity: temporal changes in abundance, life history and demography. Phil. Trans. R. Soc. B 360: 315-338. doi:10.1098/rstb.2004.1586.

Hutchings, J.A., and Fraser, D.J. 2008. The nature of fisheries- and farming-induced evolution. Mol. Ecol. 17: 294-313. doi:10.1111/j.1365-294X.2007.03485.x.

Hutchinson, W.F., Carvalho, G.R., and Rogers, S.I. 2001. Marked genetic structuring in localised spawning populations of cod Gadus morhua in the North Sea and adjoining waters, as revealed by microsatellites. Mar. Ecol. Prog. Ser. 223: 251-260.

Hutchinson, W.F., van Oosterhout, C., Rogers, S.I., and Carvalho, G.R. 2003. Temporal analysis of archived samples indicates marked genetic changes in declining North Sea cod (Gadus morhua). Proc. R. Soc. Lond. B 270: 2125-2132. doi:10.1098/rspb.2003.2493. 
Imsland, A.K. and Jonassen, T.M. 2001. Regulation of growth in turbot (Scophthalmus maximus Rafinesque) and Atlantic halibut (Hippoglossus hippoglossus L.): aspects of environment $\times$ genotype interactions. Rev. Fish Biol. Fish. 11: 71-90.

Jones, G.P., and Thompson, S.M. 1980. Social inhibition of maturation in females of the temperate wrasse Pseudolabrus celidotus and a comparison with the blennioid Tripterygion varium. Mar. Biol. 59: 247-256.

Jónsdóttir, I.G., Campana, S.E., and Marteinsdóttir, G. 2006. Stock structure of Icelandic cod Gadus morhua L. based on otolith chemistry. J. Fish Biol. 69(Supp C): 136-150. doi:10.1111/j.1095-8649.2006.01271.x.

Jónsson, J. 1954. On the Icelandic stock of cod during the years 1928-1953. Rapports et Proces-Verbaux des Reunions 136: 51-57.

Jørgensen, C., Enberg, K., Dunlop, E.S., Arlinghaus, R., Boukal, D.S., Brander, K., Ernande, B., Gårdmark, A., Johnston, F., Matsumura, S., Pardoe, H., Raab, K., Silva, A., Vainikka, A., Dieckmann, U., Heino, M., and Rijnsdorp, A.D. 2007. Managing evolving fish stocks. Science 318: 1247-1248. doi:10.1126/science.1148089.

Kause, A., Ritola, O., Paananen, T., Mäntysaari, E., and Eskelinen, U. 2003. Selection against early maturation in large rainbow trout Oncorhynchus mykiss: the quantitative genetics of sexual dimorphism and genotype-by-environment interactions. Aquaculture 228: 53-68. doi:10.1016/S0044-846(03)00244-8.

Knutsen, H., Jorde, P. E., André, C., and Stenseth, N. C. 2003. Fine-scaled geographical population structuring in highly mobile marine species: the Atlantic cod. Mol. Ecol. 12: $385-394$.

Kolstad, K., Thorland, I., Refstie, T., and Gjerde, B. 2006. Body weight, sexual maturity, and spinal deformity in strains and families of Atlantic cod (Gadus morhua) at two years of 
age at different locations along the Norwegian coast. ICES J. Mar. Sci. 63: 246-252. doi:10.1016/j.icesjms.2005.11.007.

Kraak, S.B.M. 2007. Does the probabilistic maturation reaction norm approach disentangle phenotypic plasticity from genetic change? Mar. Ecol. Prog. Ser. 335: 295-300.

Kuparinen, A., and Merilä, J. 2008. The role of fisheries-induced evolution. Science 320: $47-48$.

Law, R., and Grey, D.R. 1989. Evolution of yields from populations with age-specific cropping. Evol. Ecol. 3: 343-359.

Law, R. 2000. Fishing, selection, and phenotypic evolution. ICES J. Mar. Sci. 57: 659-668.

Law, R. 2007. Fisheries-induced evolution: present status and future directions. Mar. Ecol. Prog. Ser. 335: 271-277.

Lester, N.P., Shuter, B.J., and Abrams, P.A. 2004. Interpreting the von Bertalanffy model of somatic growth in fishes: the cost of reproduction. Proc. R. Soc. Lond. B 271: 1625-1631. doi:10.1098/rspb.2004.2778.

Marshall, C.T., and Browman, H.I. 2007. Disentangling the causes of maturation trends in exploited fish populations. Mar. Ecol. Prog. Ser. 335: 249-251.

Marshall, C.T., and McAdam, B.J. 2007. Integrated perspectives on genetic and environmental effects on maturation can reduce potential errors of inference. Mar. Ecol. Prog. Ser. 335: 301-310.

Marteinsdóttir, G., and Begg, G.A. 2002. Essential relationships incorporating the influence of age, size and condition on variables required for estimation of reproductive potential in Atlantic cod Gadus morhua. Mar. Ecol. Prog. Ser. 235: 235-256.

Marteinsdóttir, G., and Thórarinsson, K. 1998. Improving the stock-recruitment relationship in Icelandic cod (Gadus morhua) by including age diversity of spawners. Can. J. Fish. Aquat. Sci. 55: 1372-1377. 
Marteinsdóttir, G., Gunnarsson, B., and Suthers, I.M. 2000. Spatial variation in hatch date distributions and origin of pelagic juvenile cod in Icelandic waters. ICES J. Mar. Sci. 57: 1182-1195. doi:10.1006/jmsc.2000.0880.

Mollet, F.M., Kraak, S.B.M., and Rijnsdorp, A.D. 2007. Fisheries-induced evolutionary changes in maturation reaction norms in North Sea sole Solea solea. Mar. Ecol. Prog. Ser. 351: 189-199. doi: 10.3354/meps07138.

Morita, K., and Fukuwaka, M.A. 2006. Does size matter most? The effect of growth history on probabilistic reaction norm for salmon maturation. Evolution 60: 1516-1521.

Naish, K.A., and Hard, J.J. 2008. Bridging the gap between the genotype and the phenotype: linking genetic variation, selection and adaptation in fishes. Fish Fish. 9: 396-422.

Olsen, E.M., Lilly, G.R., Heino, M., Morgan, M.J., Brattey, J., and Dieckmann, U. 2005. Assessing changes in age and size at maturation in collapsing populations of Atlantic cod (Gadus morhua). Can. J. Fish. Aquat. Sci. 62: 811-823. doi:10.1139/F05-065.

Pálsson, Ó.K., and Thorsteinsson, V. 2003. Migration patterns, ambient temperature, and growth of Icelandic cod (Gadus morhua): evidence from storage tag data. Can. J. Fish. Aquat. Sci. 60: 1409-1423. doi:10.1139/F03-117.

Pálsson, Ó.K., Jónsson, E., Schopka, S.A., Stefánsson, G., and Steinarsson, B.Æ. 1989. Icelandic groundfish survey data used to improve precision in stock assessments. J. Northwest Atl. Fish. Sci. 9: 53-72.

Pampoulie, C., Ruzzante, D.E., Chosson, V., Jörundsdóttir, T.D., Taylor, L., Thorsteinsson, V., Daníelsdóttir, A.K., and Marteinsdóttir, G. 2006. The genetic structure of Atlantic cod (Gadus morhua) around Iceland: insight from microsatellites, the Pan I locus, and tagging experiments. Can. J. Fish. Aquat. Sci. 63: 2660-2674. doi:10.1139/F06-150. 
Pampoulie, C., Jakobsdottir, K.B., Marteinsdóttir, G., and Thorsteinsson, V. 2008. Are vertical behaviour patterns related to the Pantophysin Locus in the Atlantic cod (Gadus morhua L.)? Behav. Genet. 38: 76-81. doi:10.1007/s10519-007-9175-y.

Pardoe, H., Thordarson, G., and Marteinsdóttir, G. 2008. Spatial and temporal trends in condition of Atlantic cod (Gadus morhua L.) on the Icelandic shelf. Mar. Ecol. Prog. Ser. 362: 261-277. doi:10.3354/meps07409.

Powles, P. 1958. Studies of reproduction and feeding of Atlantic cod (Gadus callarias L.) in the southwestern Gulf of St Lawrence. J. Fish. Res. Board of Canada. 15: 1383-1402. Reznick, D.N., and Ghalambor, C.K. 2005. Can commercial fishing cause evolution? Answers from guppies (Poecilia reticulata). Can. J. Fish. Aquat. Sci. 62: 791-801. doi:10.1139/F05-079.

Ricker, W.E. 1981. Changes in the average size and average age of Pacific salmon. Can. J. Fish. Aquat. Sci. 38: 1636-1656.

Rijnsdorp, A.D. 1990. The mechanism of energy allocation over reproduction and somatic growth in female North Sea plaice, Pleuronectes platessa L. Neth. J. Sea Res. 25: $279-289$.

Roff, D.A. 1983. An allocation model of growth and reproduction in fish. Can. J. Fish. Aquat. Sci. 40: $1395-1404$.

Ruzzante, D.E., Mariani, S., Bekkevold, D., Andre, C., Mosegaard, H., Clausen, L.A.W., Dahlgren, T.G., Hutchinson, W.F., Hatfield, E.M.C., Torstensen, E., Brigham, J., Simmonds, E.J., Laikre, L., Larsson, L.C., Stet, R.J.M., Ryman, N., and Carvalho, G.R. 2006. Biocomplexity in a highly migratory pelagic marine fish, Atlantic herring. Proc. Natl. Acad. Sci. USA 273: 1459-1464. 
Sinclair, A.F., Swain, D.P., and Hanson, J. M. 2002. Measuring changes in the direction and magnitude of size-selective mortality in a commercial fish population. Can. J. Fish. Aquat. Sci. 59: 361-371. doi:10.1139/F02-015.

Stearns, S.C. 1992. The Evolution of Life Histories. Oxford University Press, New York.

Stenseth, N.C., and Rouyer, T. 2008. Destabilized fish stocks. Nature 452: 825-826. doi:10.1038/452825a.

Stergiou, K.I. 2002. Overfishing, tropicalization of fish stocks, uncertainty and ecosystem management: resharpening Ockham's razor. Fish. Res. 55: 1-9.

Stokes, K., and Law, R. 2000. Fishing as an evolutionary force. Mar. Ecol. Prog. Ser. 208: $307-309$.

Swain, D. P., Sinclair, A. F., and Hanson, J. M. 2007. Evolutionary response to size-selective mortality in an exploited fish population. Proc. R. Soc. Lond. B 274: 1015-1022. doi:10.1098/rspb.2006.0275.

Thórarinsson, K., and Jóhannesson, G. 1997. Correcting for variation in catchability: maturity-related catchability variation in Icelandic cod. ICES J. Mar. Sci. 54: 787-796.

Thorpe, J.E. 2007. Maturation responses of salmonids to changing developmental opportunities. Mar. Ecol. Prog. Ser. 335: 285-288.

Trippel, E.A. 1995. Age at maturity as a stress indicator in fisheries. BioScience 45: 759-771.

Vainikka, A., Gårdmark, A., Bland, B., and Hjelm, J. 2009. Two- and three-dimensional maturation reaction norms for the eastern Baltic cod, Gadus morhua. ICES J. Mar. Sci. 66: $248-257$.

Vitale, F., Svedäng, H., and Cardinale, M. 2006. Histological analysis invalidates macroscopically determined maturity ogives of the Kattegat cod (Gadus morhua) and suggests new proxies for estimating maturity status of individual fish. ICES J. Mar. Sci. 63: 485-492. doi:10.1016/j.icesjms.2005.09.001. 
Walsh, M., Munch, S., Chiba, S., and Conover, D. 2006. Maladaptive changes in multiple traits caused by fishing: impediments to population recovery. Ecol. Lett. 9: 142-148.

Wright, P.J. 2007. Understanding the maturation process for field investigations of fisheriesinduced evolution. Mar. Ecol. Prog. Ser. 335: 279-283.

Yoneda, M., and Wright, P.J. 2005. Effects of varying temperature and food availability on growth and reproduction in first-time spawning female Atlantic cod. J. Fish Biol. 67: 1225-1241. doi:10.1111/j.1095-8649.2005.00819.x. 
Table 1. Data summary. For each time period and data type (survey data SD, commercial data $\mathrm{CD}$ and groundfish survey data GSD): age-specific total sample size and mean per cohort, mean proportion mature for females $(\mathrm{F})$ and males $(\mathrm{M})$. Percentage of data for females $(\% \mathrm{~F})$ is also shown.

\begin{tabular}{|c|c|c|c|c|c|c|c|c|}
\hline \multirow[t]{2}{*}{ Data type, Years } & \multicolumn{6}{|c|}{ Age } & \multirow[b]{2}{*}{ Total } & \multirow[b]{2}{*}{$\% \mathrm{~F}$} \\
\hline & 3 & 4 & 5 & 6 & 7 & 8 & & \\
\hline \multicolumn{9}{|c|}{ SD, 1967-1984 (Fig. 2a) } \\
\hline Total & 2743 & 5032 & 4667 & 4229 & 3515 & 2178 & 22364 & 48 \\
\hline Mean per cohort ${ }^{1}$ & 115 & 298 & 271 & 267 & 220 & 112 & & \\
\hline Mean $\%$ mature $(F)^{1}$ & 0 & 2 & 12 & 35 & 61 & 82 & 29 & \\
\hline Mean $\%$ mature $(\mathrm{M})^{1}$ & 1 & 4 & 20 & 54 & 78 & 90 & 40 & \\
\hline \multicolumn{9}{|c|}{ CD, 1977-1995 (Fig. 2b) } \\
\hline Total & 183 & 2446 & 4698 & 3971 & 2615 & 924 & 14837 & 50 \\
\hline Mean per cohort ${ }^{2}$ & 8 & 116 & 270 & 241 & 165 & 48 & & \\
\hline Mean $\%$ mature $(\mathrm{F})^{2}$ & 5 & 10 & 15 & 30 & 53 & 66 & 27 & \\
\hline Mean $\%$ mature $(\mathrm{M})^{2}$ & 5 & 9 & 23 & 41 & 64 & 73 & 35 & \\
\hline \multicolumn{9}{|c|}{ GSD/SD, 1989-2007 (Fig. 2c) } \\
\hline Total & 11373 & 14650 & 13899 & 11413 & 7375 & 3375 & 62085 & 50 \\
\hline Mean per cohort ${ }^{3}$ & 574 & 762 & 694 & 579 & 374 & 180 & & \\
\hline Mean $\%$ mature $(F)^{3}$ & 0 & 5 & 22 & 52 & 75 & 86 & 37 & \\
\hline Mean $\%$ mature $(M)^{3}$ & 1 & 13 & 42 & 66 & 81 & 90 & 50 & \\
\hline
\end{tabular}

For cohorts: ${ }^{1} 1964-1976{ }^{2} 1974-1987^{3} 1985-1999$ 
Table 2. Estimated change (weighted linear regression of estimates from research survey data) in PMRN midpoints (Lp50s) between 1964 and 1999 cohorts.

\section{Estimated change in Lp50}

\begin{tabular}{ccccc} 
Age & Sex & cm & \%.year ${ }^{-1}$ & P \\
4 & F & $6.1^{a}$ & 0.20 & 0.2091 \\
4 & M & -12.9 & -0.36 & 0.0101 \\
5 & F & -2.3 & -0.07 & 0.0535 \\
5 & M & -10.5 & -0.33 & 0.0052 \\
6 & F & -6.2 & -0.22 & 0.0192 \\
6 & M & -6.4 & -0.23 & 0.0233 \\
7 & F & -8.4 & -0.33 & 0.0027 \\
7 & M & -9.6 & -0.44 & 0.0157 \\
8 & F & -14.3 & -0.63 & 0.0002 \\
8 & M & -10.7 & -0.52 & 0.0222 \\
\hline${ }^{a}$ no estimate for 1964 cohort &
\end{tabular}


Table 3. Changes in average length between 1964 and 1999 cohorts observed in PMRN analyses (see Fig. 3), compared to those predicted by a simulation exercise examining the effects of earlier maturation on growth. Predictions made using 1) an average energetic GSI and 2) a 'high' energetic GSI (see Methods 'Effect of earlier maturation on growth' section).

\begin{tabular}{ccccc}
\hline & & Observed & \multicolumn{2}{c}{ Predicted change $(\mathrm{cm})$} \\
Age & Sex & change $(\mathrm{cm})$ & average GSI & high GSI \\
4 & F & -5.2 & -0.1 & -0.2 \\
4 & M & -5.3 & -0.4 & -0.6 \\
5 & F & -4.3 & -0.6 & -1.4 \\
5 & M & -5.1 & -1.7 & -2.6 \\
6 & F & -3.7 & -1.8 & -3.8 \\
6 & M & -4.4 & -3.3 & -4.9 \\
7 & F & -2.1 & -2.4 & -5.1 \\
7 & M & -2.8 & -3.8 & -5.5 \\
8 & F & -3.5 & -2.3 & -4.6 \\
8 & M & -4.0 & -3.5 & -5.0 \\
\hline
\end{tabular}


Fig. 1. Average fishing mortality (ages $5-10$ ) and biomass (solid line: total for ages 4+, dashed line: spawning stock) of the Icelandic cod stock since 1955 (Anonymous 2007).

Fig. 2. Sampling locations for three time periods and data types (see Table 1). Bar plots show percentage $(\%)$ of samples from southern (open hatched) and northern (filled black) region. The $500 \mathrm{~m}$ depth contour is marked (thin line).

Fig. 3. Average length (cm) of (a) female and (b) male Icelandic cod aged $4-8$ years (bottom to top line), estimated for PMRN analyses of survey (black lines) and commercial (grey lines) data. Predictions made from a GLM model (equation 3).

Fig. 4. Estimated trends in growth from GLM (see Methods 'Growth trends' section) of survey data, shown for immature cod (top panels) of ages (a) 4 and (b) 5 and mature cod (bottom panels) of ages (c) 6 and (d) 7. For each group, average length is predicted for males (solid lines) and females (dashed lined) in the northern (lower thin lines) and southern (upper thick lines) region.

Fig. 5. Probabilistic maturation reaction norm midpoints (Lp50s) for female and male Icelandic cod (ages 4-8) of cohorts 1985 - 1999 (plotted by year). Lp50s were estimated using un-weighted $(\boldsymbol{\Delta})$ and weighted $(\bullet)$ research survey data (see Materials and Methods). Bootstrapped 95\% confidence intervals are shown for weighted data (grey vertical bars) only; see Figure 7 for confidence intervals of un-weighted data. Note different scales on y-axes (set to minimum possible scale).

Fig. 6. Probabilistic maturation reaction norms of (a) female and (b) male Icelandic cod, estimated as the average Lp50 for: cohorts 1970 - 1973 (crosses on black dotted line), cohorts 1980 - 1983 (triangles on grey solid line), and cohorts 1996 - 1999 (squares on black dashed line). Grey lines show estimates from commercial data; considered less representative than survey data (black lines). Lines without points show the average length-at-age for the corresponding cohorts. 
Fig. 7. Probabilistic maturation reaction norm midpoints (Lp50s) of (a) - (e) female and (f) (j) male Icelandic cod, aged $4-8$ years, with bootstrapped $95 \%$ confidence intervals (vertical bars) for survey $(\boldsymbol{\Delta})$ and commercial $(\bullet)$ data. Significant linear regressions of Lp50s estimated from research survey data (GSD, SD), weighted by the inverse bootstrap variances, are shown (---).

Fig. 8. Average condition: (a) Hepatosomatic index (HSI, \%) and (b) Relative body condition index (Kr), for immature (filled circles) and mature cod (filled squares) in the spring (March), and all cod in the autumn (open triangles, October). Temperature $\left({ }^{\circ} \mathrm{C}\right)$ in $(\mathrm{c})$ northern (Siglunes section) and (d) south-western (Selvogsbanki) Icelandic waters, measurements from: 50 - $150 \mathrm{~m}$ in May/June (thin lines, north/southwest), 50 - $150 \mathrm{~m}$ in July - September (bold line, north), $0-200 \mathrm{~m}$ in July-September (bold line, southwest). 
Fig. 1.
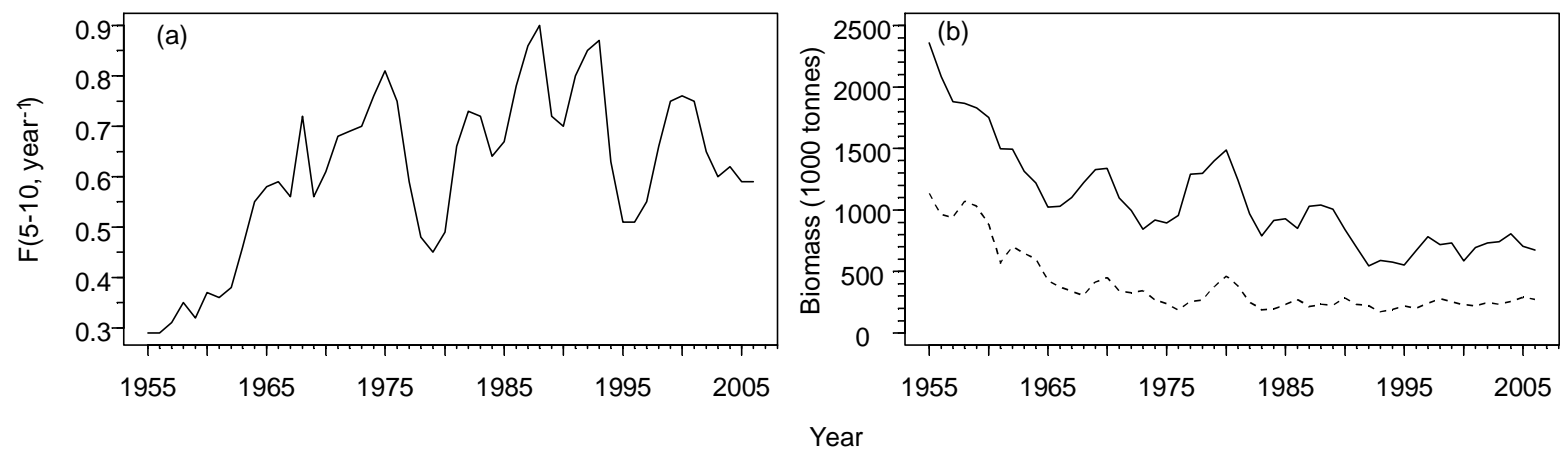
Fig. 2.
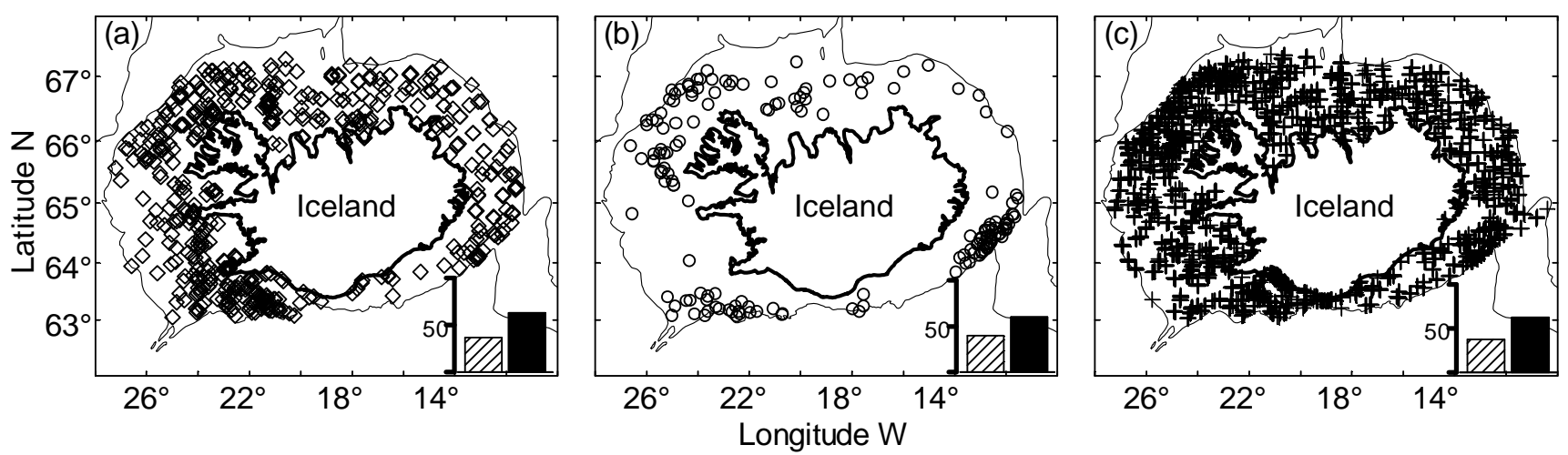
Fig. 3.

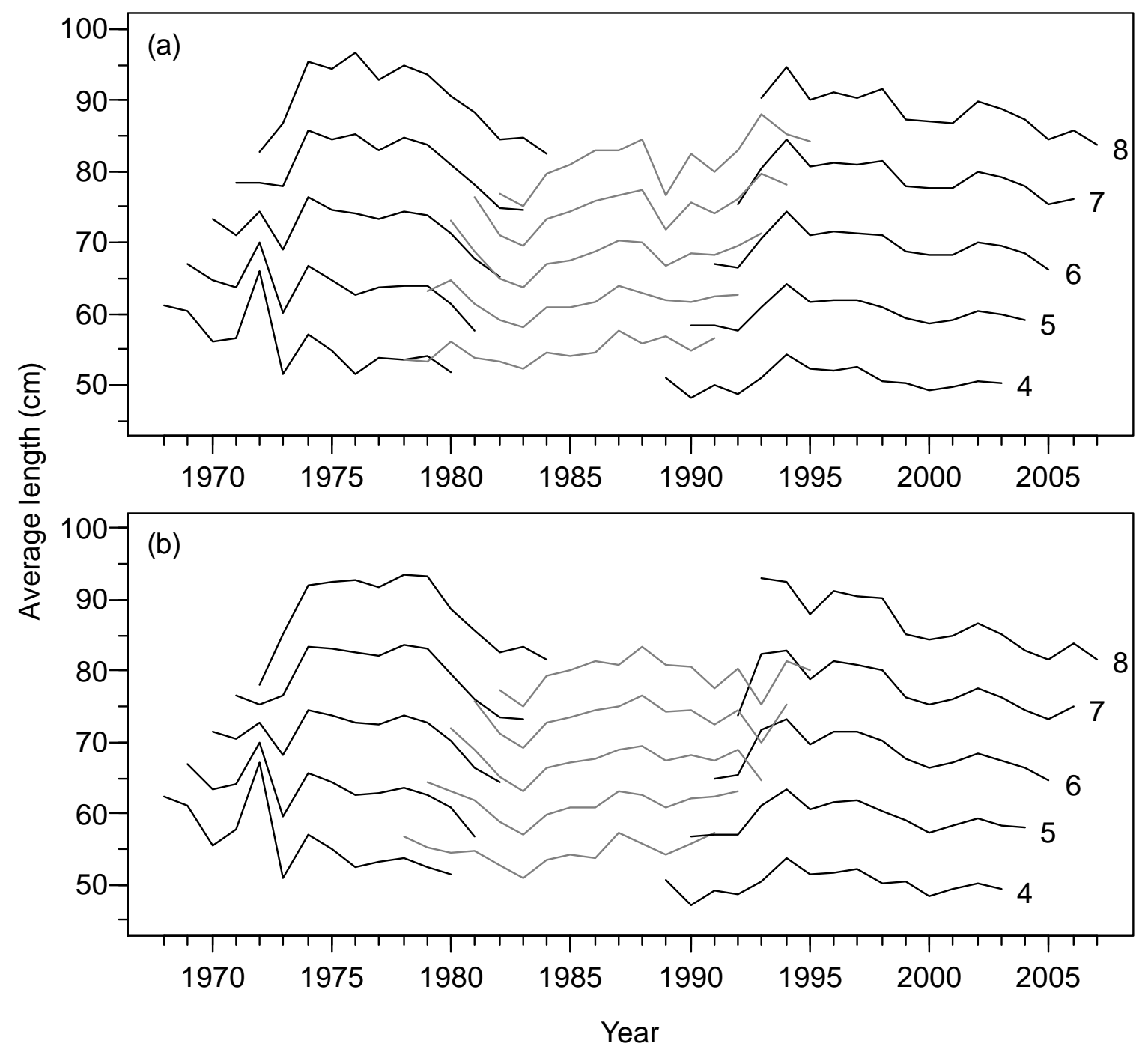


Fig. 4.
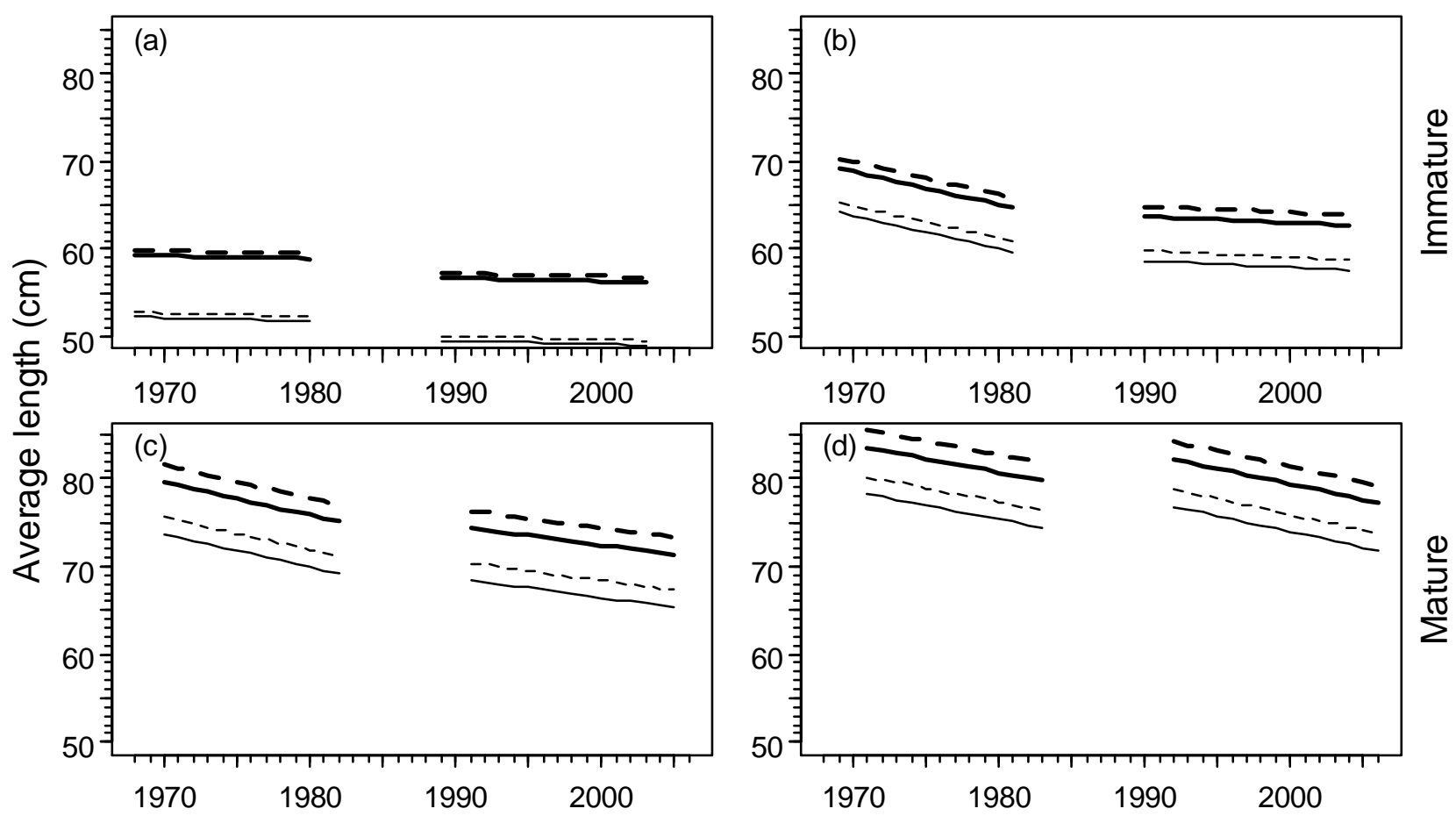

Year 
Fig. 5.

Females
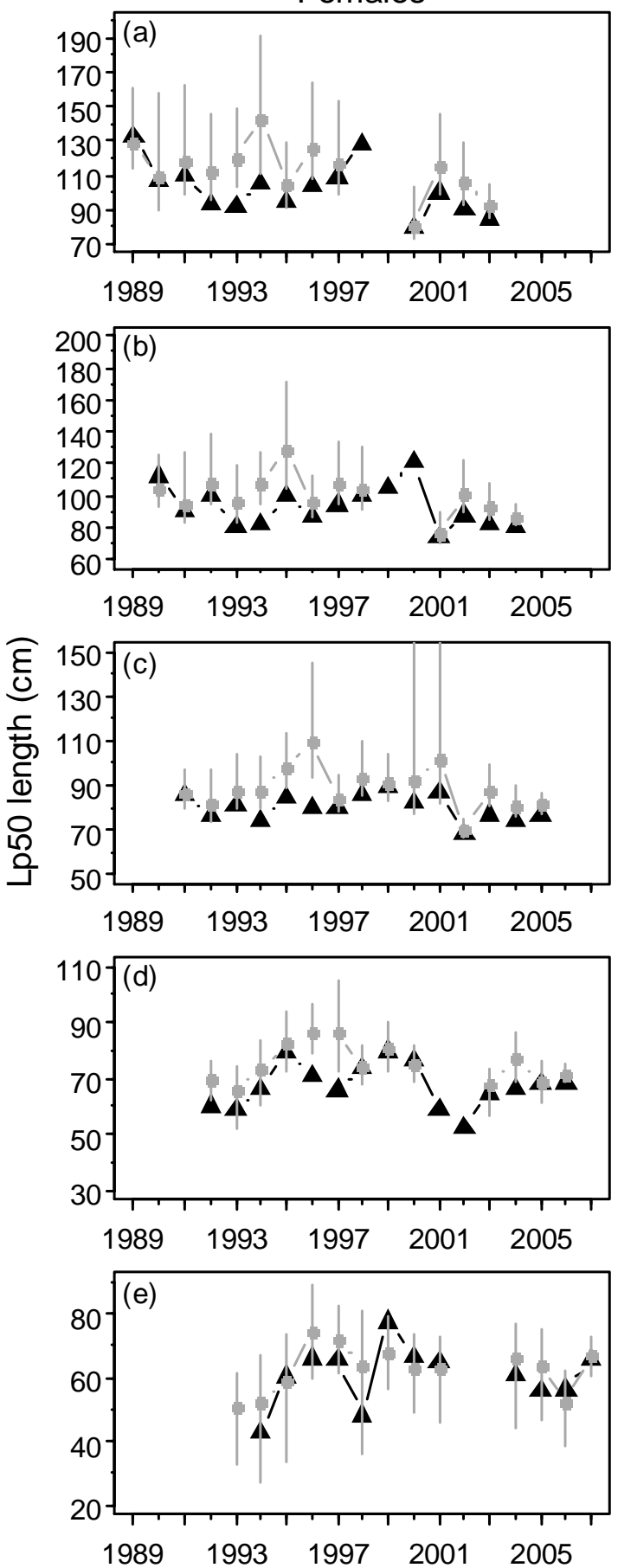

Males
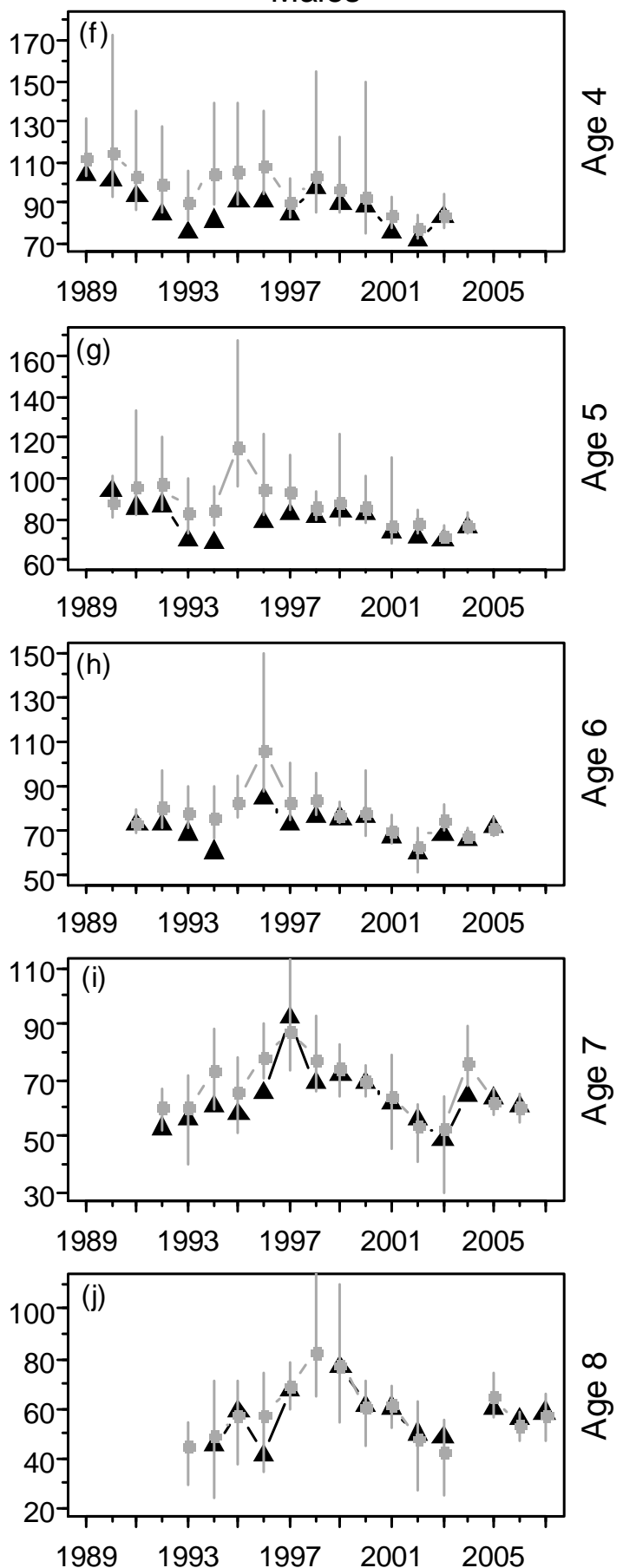

Year 
Fig. 6.
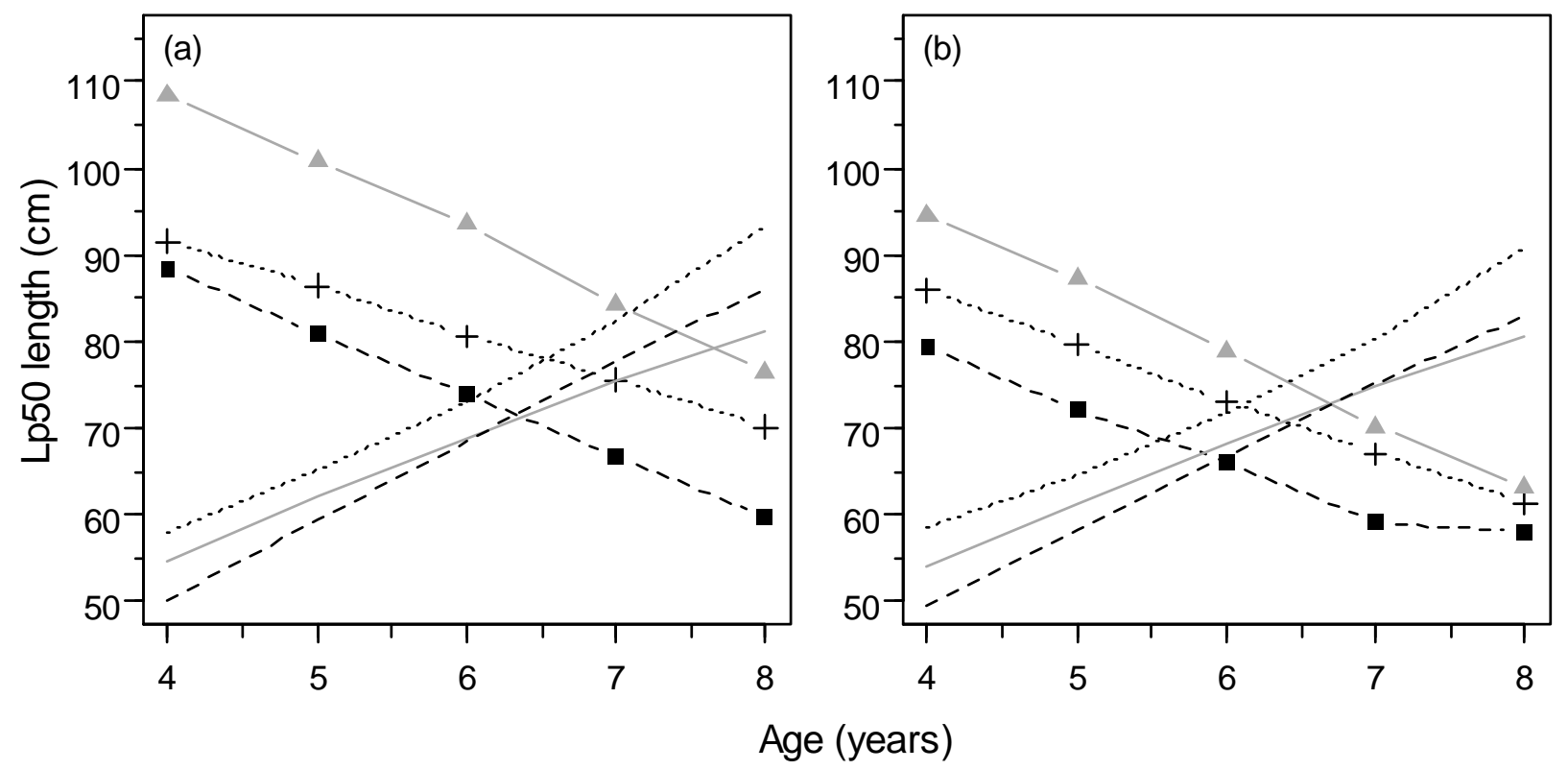
Fig. 7.

Females
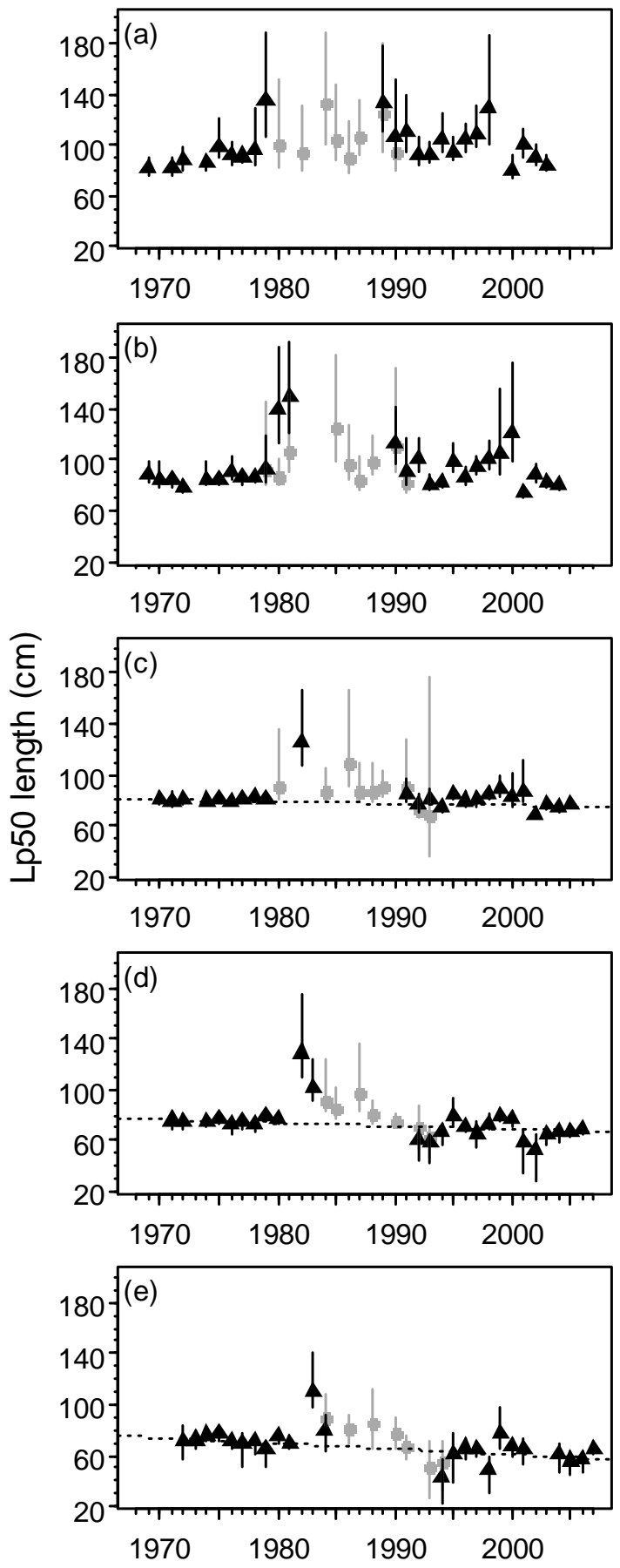

Males
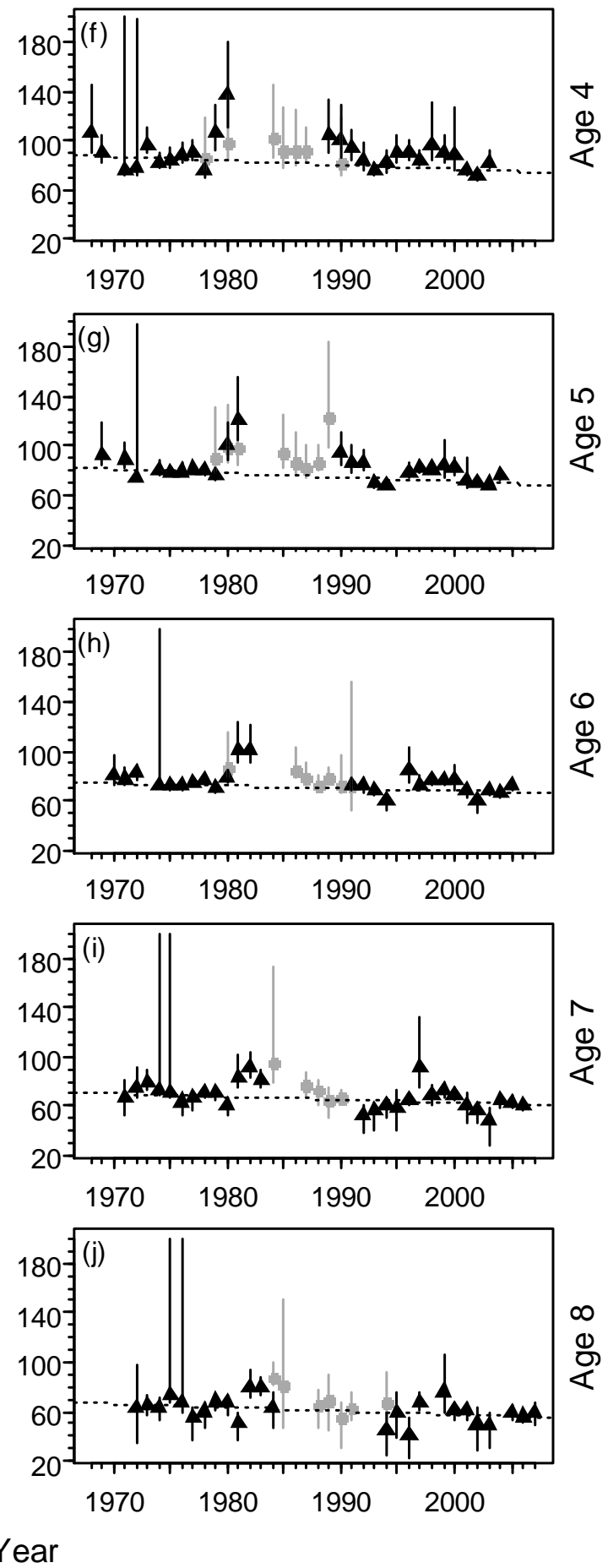
Fig. 8.
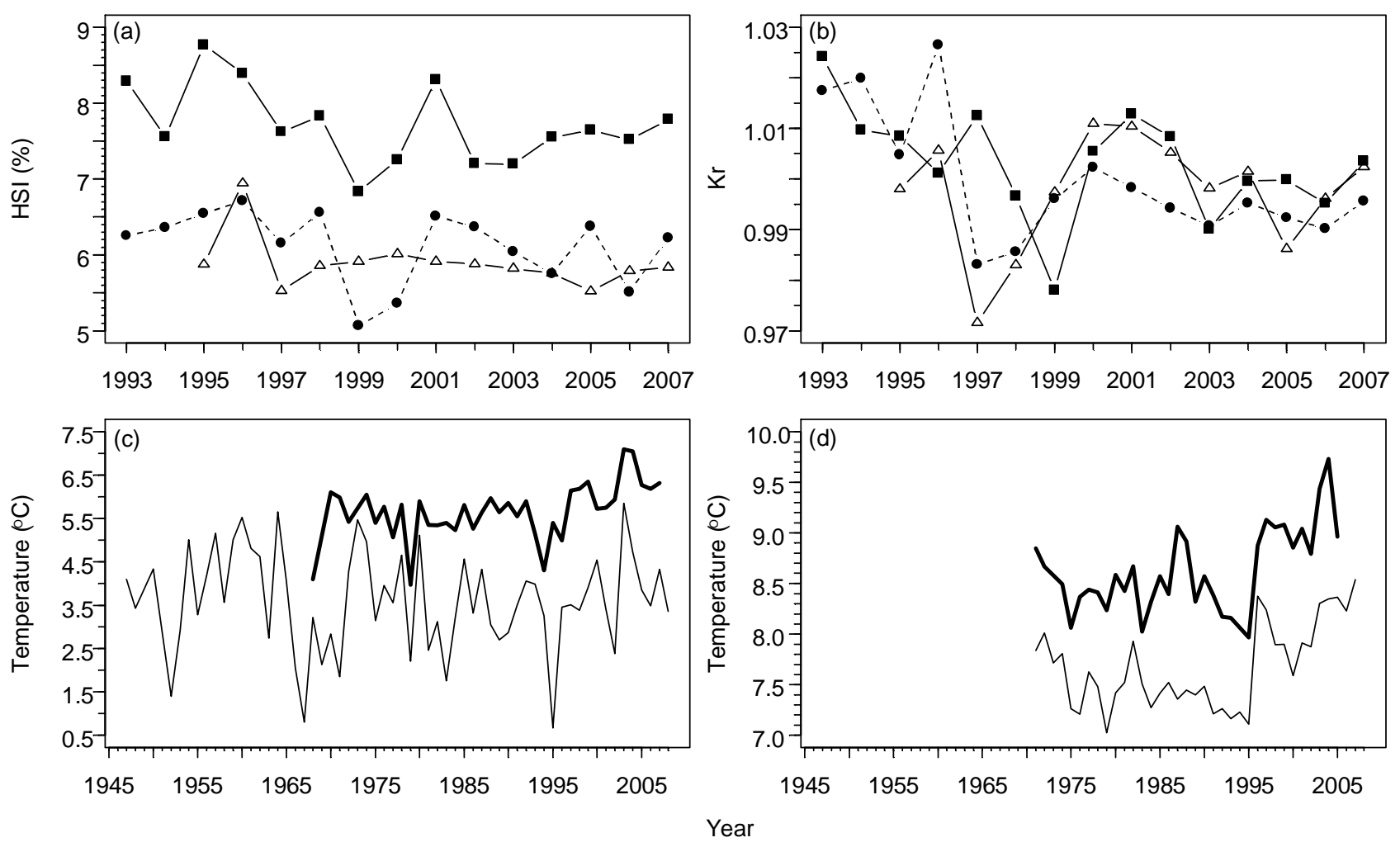